\title{
The Role of Precipitation in Controlling the Transition from Stratocumulus to Cumulus Clouds in a Northern Hemisphere Cold-Air Outbreak ${ }^{\mathfrak{d}}$
}

\author{
Steven J. Abel, Ian A. Boutle, Kirk Waite, Stuart Fox, \\ PHILIP R. A. BROWN, AND RICHARD COTTON \\ Met Office, Exeter, United Kingdom \\ Gary Lloyd, Tom W. Choularton, AND Keith N. Bower \\ School of Earth, Atmospheric and Environmental Sciences, University of Manchester, Manchester, United Kingdom
}

(Manuscript received 15 December 2016, in final form 19 April 2017)

\begin{abstract}
Aircraft observations in a cold-air outbreak to the north of the United Kingdom are used to examine the boundary layer and cloud properties in an overcast mixed-phase stratocumulus cloud layer and across the transition to more broken open-cellular convection. The stratocumulus cloud is primarily composed of liquid drops with small concentrations of ice particles and there is a switch to more glaciated conditions in the shallow cumulus clouds downwind. The rapid change in cloud morphology is accompanied by enhanced precipitation with secondary ice processes becoming active and greater thermodynamic gradients in the subcloud layer. The measurements also show a removal of boundary layer accumulation mode aerosols via precipitation processes across the transition that are similar to those observed in the subtropics in pockets of open cells. Simulations using a convection-permitting (1.5-km grid spacing) regional version of the Met Office Unified Model were able to reproduce many of the salient features of the cloud field although the liquid water path in the stratiform region was too low. Sensitivity studies showed that ice was too active at removing supercooled liquid water from the cloud layer and that improvements could be made by limiting the overlap between the liquid water and ice phases. Precipitation appears to be the key mechanism responsible for initiating the transition from closed- to open-cellular convection by decoupling the boundary layer and depleting liquid water from the stratiform cloud.
\end{abstract}

\section{Introduction}

Cold-air outbreaks in the midlatitudes draw cold polar or continental air masses over a relatively warm ocean, resulting in a rapid increase in the surface fluxes of heat and moisture from the sea surface and the subsequent development of extensive boundary layer clouds (Brümmer 1996, 1999; Kolstad et al. 2009; Fletcher et al. 2016). As the boundary layer structure evolves over the ocean, there are often rapid changes in the morphology of the cloud field that can lead to marked changes in the radiative effects of the

\footnotetext{
O) Supplemental information related to this paper is available at the Journals Online website: http://dx.doi.org/10.1175/ JAS-D-16-0362.s1.
}

Corresponding author: Steven J. Abel, steven.abel@metoffice. gov.uk clouds-for example, across transitions from overcast stratocumulus clouds to open-cellular convection downwind [see Fig. 1b and Field et al. (2014)]. Modeling both the cloud microphysical properties and the morphological characteristics of the cloud field in cold-air outbreaks therefore plays an important role in being able to accurately simulate the top-of-the-atmosphere and surface energy budgets in both climate and numerical weather prediction (NWP) models.

This has been highlighted in a multitude of studies demonstrating that most of the current state-of-the-art climate and global NWP models suffer from significant surface and top of the atmosphere radiative flux biases in the Southern Ocean. A significant contribution to this bias arises from a poor representation of boundary layer clouds in the cold-air sector of midlatitude depressions, with models typically underestimating cloud fraction and cloud albedo (Bodas-Salcedo et al. 2012, 2014, 2016; Williams et al. 2013; Forbes and Ahlgrimm 2014; 
Kay et al. 2016). The problem is not unique to coarsehorizontal-resolution global models. A recent model intercomparison study that evaluated nine leading regional NWP models (horizontal resolutions varied from 1 to $16 \mathrm{~km}$ ) clearly demonstrated that the models cannot simulate the stratocumulus cloud region of cold-air outbreaks (Field et al. 2017). The simulated cloud field was too broken and the reflected shortwave radiation and cloud liquid water contents were too low when compared to satellite observations. As the horizontal resolution increased, the models began to simulate explicit convection in the stratiform regime and the simulated cloud morphology became even more broken. In contrast, the models tended to better represent the morphology and properties of the convective clouds that were downwind of the more stratiform cloud deck. Field et al. (2014) show that, in a regional-scale model run at a horizontal resolution of $1.5 \mathrm{~km}$ for the same cold-air-outbreak case in the North Atlantic, improvements in the simulation of the stratiform cloud layer could be achieved by modifying the model cloud microphysics and boundary layer schemes, but these changes were not a panacea and that significant biases still existed. The model improvements that resulted from this comparison against observations did however lead to a reduction in the Southern Ocean bias when implemented in a coarser-horizontal-resolution climate version of the same model (Bodas-Salcedo et al. 2012).

Much of the challenge for numerical modeling arises from the need to represent complex interactions between the dynamics, cloud microphysics, and convection in the shallow boundary layers often found in cold-air outbreaks. Furthermore, the clouds are typically mixed phase in nature (they contain supercooled liquid water and ice) (Field et al. 2014; Bodas-Salcedo et al. 2016), for which there are a myriad of competing and poorly understood small-scale processes that need to be parameterized in models (Morrison et al. 2012). There have to date been very few in situ observations made in the mixed-phase stratiform region of cold-air outbreaks and in transition regions where the morphological structure of the cloud field changes from a stratiform cloud deck to more open-cellular convection, resulting in a lack of observational constraints to use for improving models. For example, the in situ observations of Field et al. (2014) were made farther downwind in more developed cumulus clouds. There has been a wealth of studies on similar transitions from stratocumulus to open-cellular convection in the subtropics, which in principle are much simpler as they contain no ice, but model studies still exhibit large uncertainties and model dependencies (e.g., R. A. J. Neggers et al. 2017, manuscript submitted to J. Adv. Model. Earth Syst.). An open question is whether similar processes are involved in the breakup of the stratiform cloud in cold-air outbreaks.

In this study we will present in situ research aircraft and satellite observations of a cold-air-outbreak case study to the north of the United Kingdom, which exhibited an area of stratiform cloud that evolved into open-cellular convection downwind. The focus of the observations was to make measurements of the cloud properties and boundary layer structure in both the stratiform cloud region and across the transition in cloud morphology. The observations are then used to evaluate cloud-resolving model simulations of the case study and to test the impact of modifications designed to improve the model performance. Finally the model is used in conjunction with the observations to examine the processes responsible for the breakup of the stratiform cloud deck. The paper is structured as follows. Section 2 presents details on the observations and the model used in this study. The case study is then introduced in section 3. The main results of this study are presented in section 4 and a discussion and conclusions in section 5 .

\section{Data}

\section{a. Aircraft instrumentation}

The Facility for Airborne Atmospheric Measurements (FAAM) BAe-146 research aircraft (http:// www.faam.ac.uk) has a comprehensive suite of thermodynamic, radiometric, cloud physics, and aerosol instrumentation. The instrumentation pertinent to this study includes the following. The number concentration and sizing of cloud drops $(2-50 \mu \mathrm{m})$ were measured using a cloud droplet probe (CDP) and larger precipitation-sized particles were measured with a two-dimensional stereo probe (2DS) $(10 \mu \mathrm{m}-$ $1.28 \mathrm{~mm})$ and a cloud imaging probe (CIP) $(100 \mu \mathrm{m}-$ $6.4 \mathrm{~mm}$ ). All of the cloud physics probes were fitted with antishatter tips (Korolev et al. 2013a) and particle interarrival time filtering was also employed on the 2DS and CIP-100 data to further reduce any measurement biases that result from the shattering of large particles upstream of the probes sample volume (Field et al. 2006). The circularity $C$ of particles larger than $\sim 80 \mu \mathrm{m}$ measured with the 2DS are classified using the measured particle perimeter $P$ and particle area $A$, where $C=P^{2} /(4 \pi A)$ (Crosier et al. 2011). The highly irregular class of particles, which we define as particles that have a circularity larger than 1.4 are 
used as proxy for ice number concentration. Accumulation mode aerosol particles $(0.1-3.0 \mu \mathrm{m})$ were measured with a passive cavity aerosol spectrometer probe (PCASP-100X). The PCASP data are screened for potential artifacts that result from shattering of drops by filtering out data at times when the CDP number concentration $>1 \mathrm{~cm}^{-3}$ and the Nevzorov TWC $>0.01 \mathrm{~g} \mathrm{~m}^{-3}$. An aircraft integrated meteorological measurement system (AIMMS-20) was used to make measurements of the $3 \mathrm{D}$ wind components (Beswick et al. 2008). The AIMMS-20, PCASP, CDP, 2DS, and CIP-100 were all mounted on underwing pylons. Ambient air temperature was measured using a deiced Rosemount/Goodrich type 102 total air temperature sensor. Liquid water content (LWC) and total condensed water content (TWC) were measured using a deep cone Nevzorov hot wire probe (Korolev et al. 2013b). The total water probe (Nicholls et al. 1990) was used to measure the total water content (vapor plus condensed water $q_{t}$ ).

Previous studies (e.g., English 1995; Zuidema et al. 2012) have demonstrated that airborne millimeterwave radiometers can be used to retrieve liquid water path (LWP) in stratocumulus clouds. In this study, we use downward-looking views from the 89- and $157-\mathrm{GHz}$ channels on the Microwave Airborne Radiometer Scanning System (MARSS) radiometer (McGrath and Hewison 2001). Over ocean, the downward-looking measurements are sensitive to liquid water both above and below the aircraft owing to reflection from the sea surface, so they can provide a continuous retrieval through the whole flight. Our retrieval method is broadly similar to that described by English (1995), using the Newtonian iteration scheme following Rodgers (1976). Radiative transfer simulations are performed using the Atmospheric Radiative Transfer Simulator (ARTS) model (Eriksson et al. 2011), with background profiles of temperature and humidity taken from the Met Office Global NWP model. The surface emissivity is calculated using FASTEM (Liu et al. 2011a), with the surface temperature and wind speed taken from aircraft measurements during lowlevel runs. The cloud liquid water content is assumed to increase linearly from cloud base to cloud top, which is a good approximation in the stratiform region of this cold-air outbreak (see Fig. 4), and the altitudes of the cloud base and top are obtained from aircraft profiles. Cloud liquid water absorption is calculated using the Ellison (2007) model, which has been shown to be appropriate for supercooled liquid water at the MARSS frequencies (Turner et al. 2016). The retrieved parameters are the liquid water path and the columnintegrated water vapor, which are used to scale the background profiles of liquid water content and water vapor in the forward model.

\section{b. Satellite data}

High-resolution visible data from the geostationary Meteosat Second Generation (MSG) satellite (Schmetz et al. 2002) at a temporal resolution of $30 \mathrm{~min}$ are utilized to track how the cloud field changed during the aircraft flight. This is complemented by higher spatial resolution infrared and true-color imagery generated using level-1 data from the polar orbiting Moderate Resolution Imaging Spectroradiometer (MODIS) Aqua satellite, which had an overpass over the region of operation at 1155 UTC. Microwave based retrievals of LWP from the AMSR-2 instrument on the polarorbiting Global Change Observation Mission 1stWater (GCOM-W1) spacecraft are also utilized (version 7.2 processing). The LWP product is available on a $0.25^{\circ} \times 0.25^{\circ}$ latitude-longitude grid and has an accuracy of $25 \mathrm{~g} \mathrm{~m}^{-2}$ (Wentz and Spencer 1998). Data from overpasses at 1154 and 1336 UTC are combined to provide a more complete coverage of the region of the aircraft operations.

\section{c. Unified Model}

The Met Office Unified Model (UM) is used to conduct a series of simulations over the region covered by the aircraft observations. The simulations use a convection-permitting setup with a horizontal grid length of $1.5 \mathrm{~km}$. The domain covered an area of $900 \mathrm{~km}$ (westeast) by $1500 \mathrm{~km}$ (north-south). There are 70 vertical levels on a stretched grid, with 29 levels located below $3-\mathrm{km}$ altitude. The scientific configuration of the model matches that used for operational NWP forecasting over the United Kingdom (the UKV model configuration from March 2016). The model has evolved significantly from the version used in previous cold-air-outbreak work by Field et al. (2014), incorporating some of their recommended changes. The ice particle size distribution parameterization of Field et al. (2007) is included and improvements to warm-rain production made via changes to the autoconversion and accretion parameterizations following Boutle and Abel (2012). These are accompanied by a new representation of the raindrop particle size distribution (Abel and Boutle 2012). There have also been extensive upgrades to the model dynamics (Wood et al. 2014) and turbulence parameterization (Boutle et al. 2014). It also includes recent modifications to the ice particle riming and depositional growth rates in the microphysics scheme and inhibiting the turbulent mixing of ice by the model's boundary layer scheme. The main driver for these more recent changes was to increase the amount of liquid water content in mixed-phase clouds in 
a)

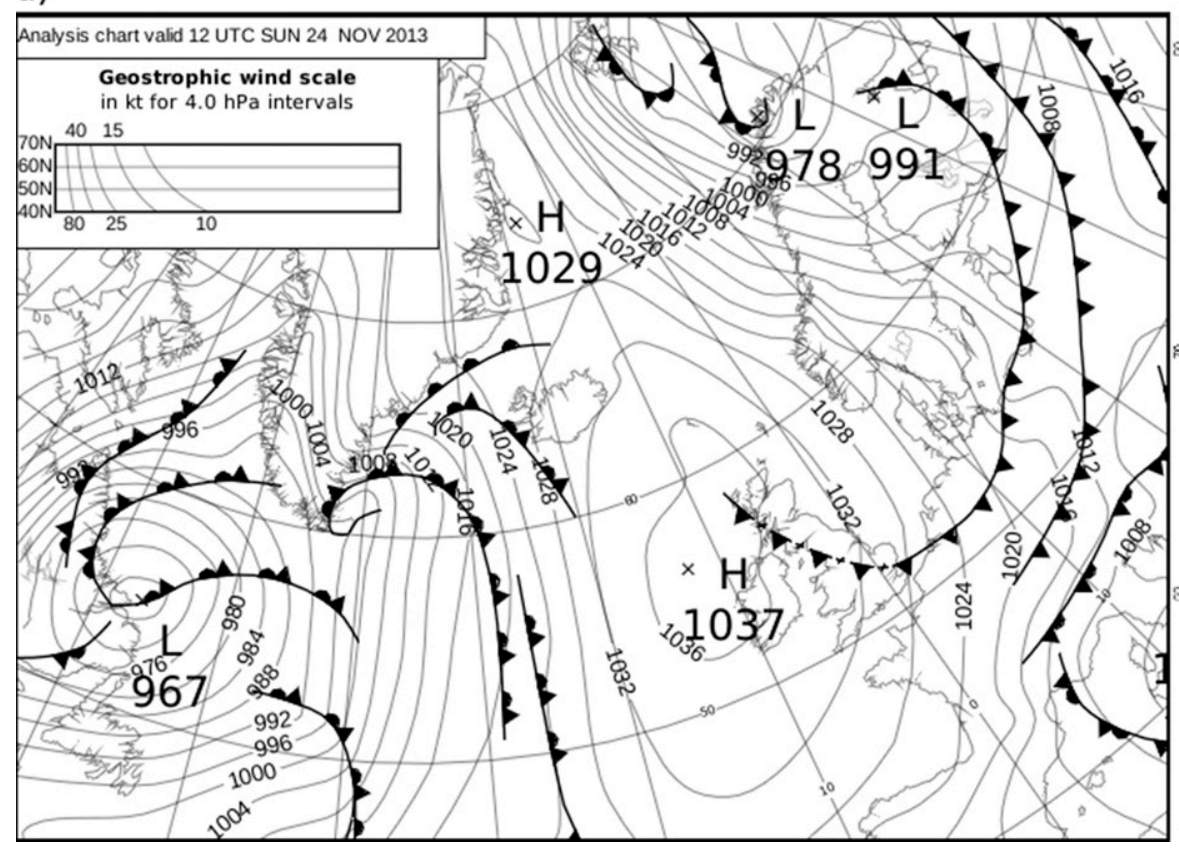

b)

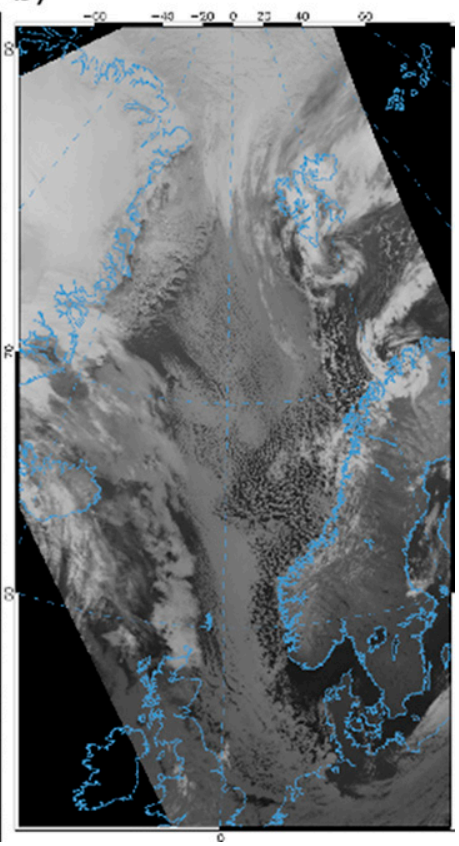

FIG. 1. (a) Met Office surface analysis chart for 1200 UTC 24 Nov 2013. (b) Composite MODIS Aqua channel 31 (10.78-11.28 $\mu \mathrm{m}$ ) thermal infrared image using data from 1150 to 1205 UTC.

the Southern Ocean (Furtado and Field 2017). The simulations start at 0000 UTC 24 November 2013 and the lateral boundary conditions are taken from a global model simulation that used the UM Global Atmosphere 6.1 (GA6.1) configuration (Walters et al. 2017).

\section{Synoptic situation}

Figure 1 shows the Met Office surface analysis chart for 1200 UTC 24 November 2013 and a corresponding infrared satellite image over the region of interest from the MODIS Aqua satellite. There was strong northerly flow on the rearward side of two polar lows that were centered on the northern Norwegian coast and to the south of the island of Svalbard. The northerly flow extended from latitudes higher than $80^{\circ} \mathrm{N}$ over the Greenland Sea, down through the Norwegian Sea, and then across Scandinavia. A component of the flow also continued down the North Sea on the eastern side of the high pressure that was centered to the west of the British Isles. The synoptic-scale sea level pressure pattern is very similar to the case study presented in Field et al. (2014) and for the composites of strong cold-air-outbreak events in this region presented by Kolstad et al. (2009), Harden et al. (2015), and Fletcher et al. (2016). The MODIS imagery shows boundary layer cloud streets forming immediately over the open water as the air moves off the sea ice along the eastern coast of Greenland as in Brümmer $(1996,1999)$. This boundary layer cloud then breaks up into more open-cellular convection downwind toward the Norwegian coastline. South of about $70^{\circ} \mathrm{N}$, close to the $0^{\circ}$ meridian, a strip of overcast stratiform cloud continues southward into the North Sea. This stratiform cloud also breaks up into more open-cellular convection along its eastern edge toward the Norwegian coastline.

\section{Results}

\section{a. Observations}

\section{1) SATELLITE DATA AND AIRCRAFT FLIGHT TRACK}

Figure 2 shows the AMSR2 satellite measurement of LWP and visible imagery from the MSG satellite, with the aircraft flight track overlaid. The aircraft took off from Prestwick airport in Scotland and transited to an area around $62^{\circ} \mathrm{N}, 1^{\circ} \mathrm{E}$ to sample the boundary layer structure and cloud properties in the stratiform cloud deck and across the transition into the more broken cumuliform cloud region. The AMSR2 LWP data show that the stratiform cloud deck in the operating area had high LWP values in excess of $300 \mathrm{~g} \mathrm{~m}^{-2}$ (the peak values averaged on a $0.25^{\circ} \times 0.25^{\circ}$ latitude-longitude grid exceeded $400 \mathrm{~g} \mathrm{~m}^{-2}$ ) and that this drops off rapidly to 

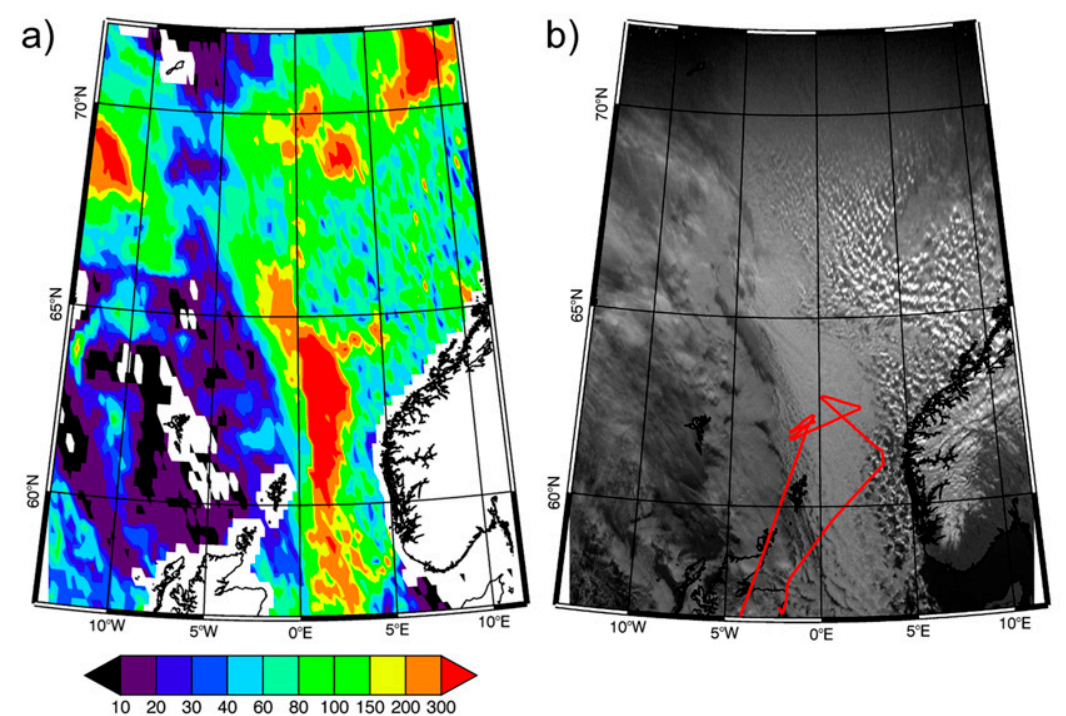

c)

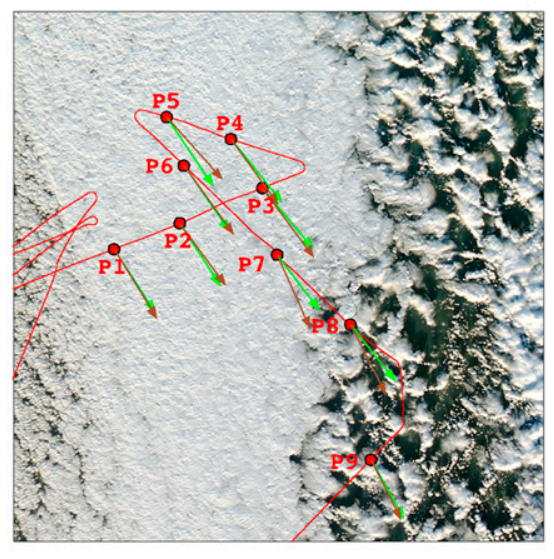

FIG. 2. (a) Liquid water path $\left(\mathrm{g} \mathrm{m}^{-2}\right)$ from AMSR2. Data are combined from satellite overpasses at 1154 and 1336 UTC. (b) Visible satellite imagery from MSG at 1200 UTC with the aircraft flight track overlaid (red). (c) MODIS Aqua true-color imagery at 1155 UTC with the aircraft flight track overlaid (red). The midpoint of the aircraft vertical profiles are shown with red circles and the observed/model mean boundary layer wind direction from each profile is shown with the brown/green arrows. The corresponding profile number is also indicated.

values less than $100 \mathrm{~g} \mathrm{~m}^{-2}$ across the transition. After sampling at low level, the aircraft then transited back to Aberdeen International Airport in Scotland.

Also shown in Fig. 2 is a MODIS Aqua true-color image that focuses in on the region of the aircraft track where the in situ observations at low level were made. There was a series of level runs below cloud and at cloud base on the western edge of the stratiform cloud deck before the aircraft performed a series of sawtooth profiles at altitudes from close to the sea surface to above the inversion at the top of the marine boundary layer. The midpoints of these profiles (labeled from P1 to P9) are shown in Fig. 2c. Also included are wind vectors indicating the mean boundary layer wind direction from each profile measured by the aircraft and from the model simulations in section 4b. Profiles P1-P3 were performed across the mean wind direction through the main stratocumulus cloud deck with the high LWP values shown in the AMSR2 data. Profiles P4 and P5 then repositioned the aircraft upwind to begin a leg approximately along the wind direction that crossed the transition into the convective cloud regime (profiles P6$\mathrm{P} 8$ ). The final profile (P9) was also in the convective cloud regime along a heading that took the aircraft back toward Aberdeen International Airport.

\section{2) Aircraft IN SITU MEASUREMENTS}

Figure 3 shows a time series of various data parameters along the flight track. The top panel plots MSG satellite high-resolution visible data updated every $30 \mathrm{~min}$. The $y$ axis plots the MSG data along a line perpendicular to the aircraft flight track; that is, the aircraft track is along the zero line shown with a red dash. Above the zero line the data are plotted to the left of the aircraft as a function of the distance from the flight track and below the zero line is to the right of the aircraft. Data are screened out during aircraft turns. This gives a visual representation of the cloud field around the aircraft measurements. For example, the aircraft approaches the transition from stratiform to more broken cloud at about 1015 UTC but remains in the overcast cloud region. The aircraft does, however, cross the transition into the convective cloud regime later in the flight at about 1100 UTC. The profile numbers shown in Fig. 2 are indicated at the top of the image. The altitude range of each of the profiles can be seen in Fig. 3b, with profiles P2P9 spanning altitudes close to the sea surface to altitudes above the cloud-topped boundary layer. The marine boundary layer depth, defined as the altitude at the base of the inversion layer, varied between 1.85 and $2.14 \mathrm{~km}$ along the flight track. The ascending profile (P1) began at cloud base and so no data are available in the subcloud layer.

Figure $3 c$ shows data from the Nevzorov LWC and TWC (liquid plus ice) sensors. The stratiform cloud layer is dominated by liquid water with peak cloud-top LWC values in excess of $0.8 \mathrm{~g} \mathrm{~m}^{-3}$, but there are some small amounts of ice present. The small amounts of ice measured by the Nevzorov are more easily seen in the subcloud data where the TWC sensor is measuring precipitating ice and the LWC sensor measures values close to zero (see also Fig. 4a). It is also evident that as the aircraft flew across the transition to the convective cloud regime (profiles P7-P9) there is a shift to the clouds 


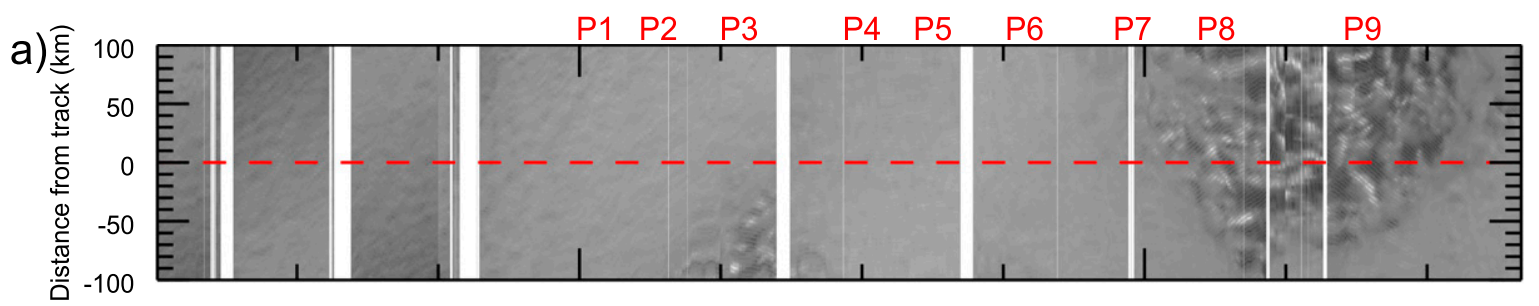

b)

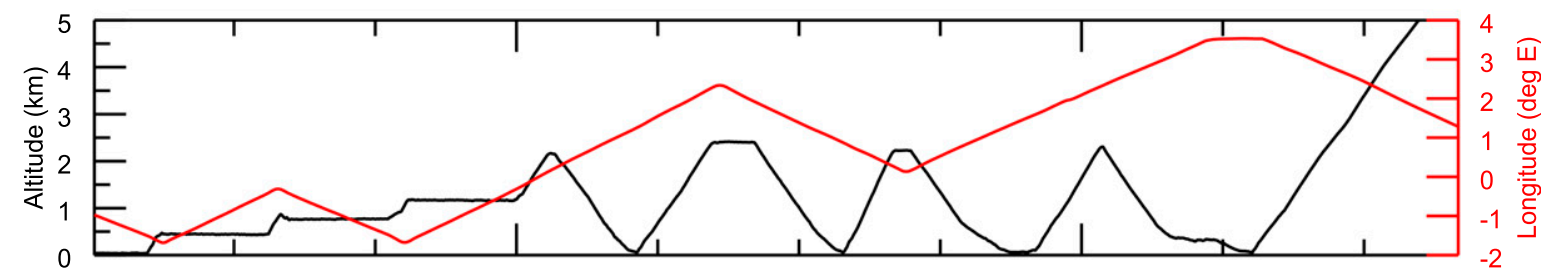

C)
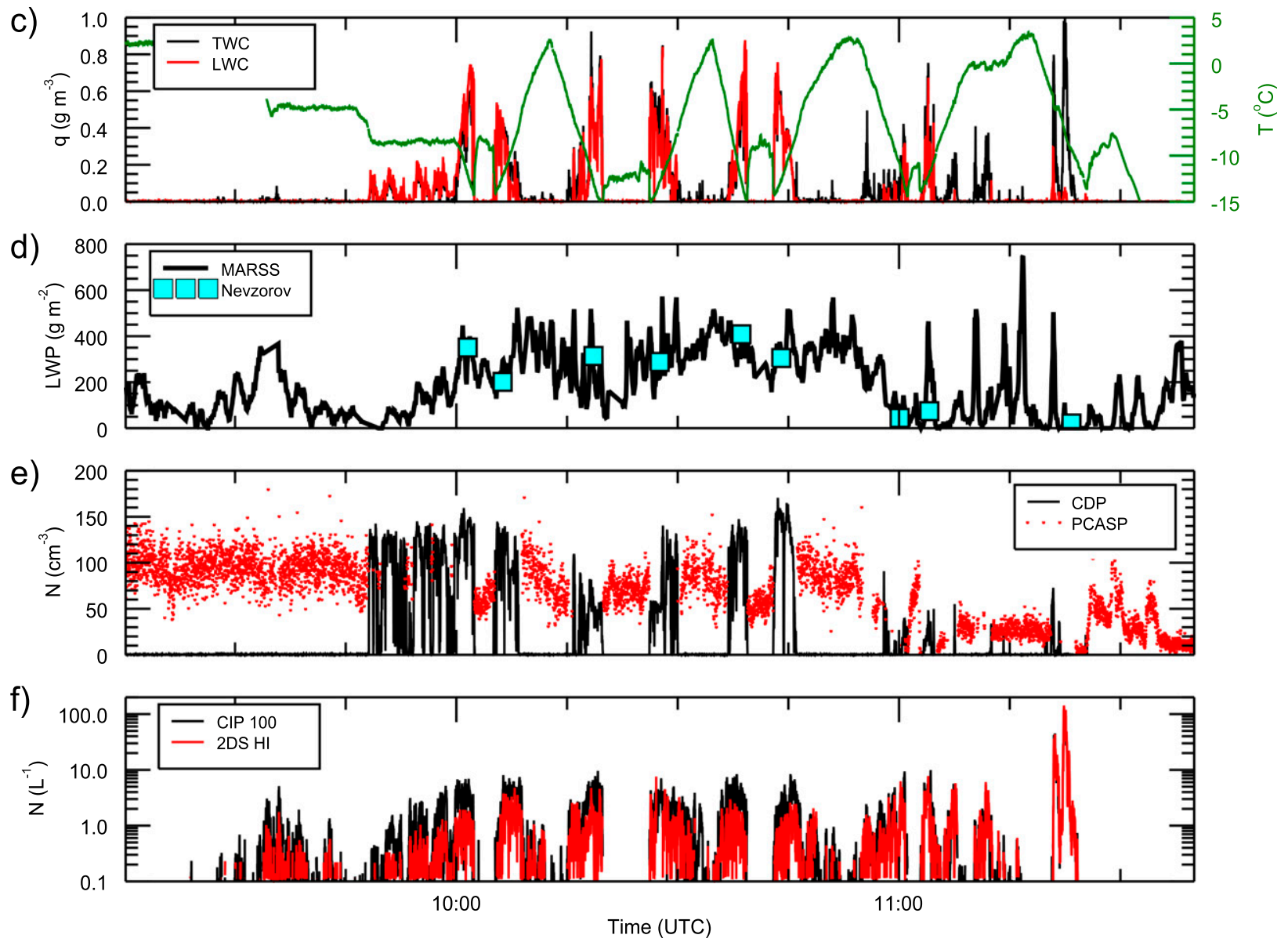

FIG. 3. Time series of data along the flight track. (a) MSG visible imagery as a function of distance from the track. Above (below) the zero line is the view to the left (right) of the aircraft. Data during aircraft turns are blanked out. The profile numbers shown in Fig. 2 are indicated above the image. (b) Aircraft altitude (black) and longitude (red). (c) Nevzorov liquid (red) and total (black) condensed water contents. Ambient air temperature is shown in green. (d) Liquid water path from MARSS (black) and the Nevzorov (cyan squares). (e) PCASP accumulation mode aerosol number concentration (red) and CDP cloud drop number concentration (black). (f) Number concentration of particles $>100 \mu \mathrm{m}$ measured by the CIP-100 (black) and of highly irregular particles measured by the 2DS (red). 
becoming glaciated, with the Nevzorov TWC sensor showing significantly higher values than the LWC sensor. Also shown in Fig. $3 \mathrm{c}$ is the measured ambient air temperature. The mean cloud-top temperature from the profiles, which coincides with the base of the temperature inversion at the top of the boundary layer, is $-14.5^{\circ} \mathrm{C}$ and this varied by less than $\pm 1^{\circ} \mathrm{C}$ across the flight.

The LWP retrieved from the MARSS radiometer and derived from integrating the Nevzorov LWC sensor during the profiles is shown in Fig. $3 \mathrm{~d}$. The agreement between the two methods from the profile data is very good $\left(R^{2}=0.91\right)$. The MARSS data show that to the western edge of the stratiform cloud deck (before profile P1), there is a strong horizontal gradient in LWP that dropped off westward. The thinning of the cloud to the west can also be inferred from the satellite imagery in Fig. 2c. The subsequent profiles in the thicker and more uniform stratiform cloud layer (profiles P1-P6) show that the LWP values were typically between about 200 and $400 \mathrm{~g} \mathrm{~m}^{-2}$. This is in good agreement with the satellite estimate shown in Fig. 2a. As the aircraft crossed the transition into the cumulus cloud regime (profiles P7-P9) the LWP becomes more variable, with the highest LWP values measured during the flight being associated with the convective cloud cores. It should be noted that the MARSS retrievals are more uncertain in the cumulus cloud regime owing to both the increased presence of large ice particles and assumptions made in the retrieval itself (see section 2a).

The cloud drop number concentration measured with the CDP $N_{d}$ and the accumulation mode aerosol number concentration measured with the PCASP $N_{a}$ are shown in Fig. 3e. In the stratiform cloud regime the cloud $N_{d}$ is typically around $140 \mathrm{~cm}^{-3}$ and the subcloud $N_{a}$ around $100 \mathrm{~cm}^{-3}$. Examination of the PCASP size spectra data (not shown) shows that the mode of the size distribution resides close to the minimum particle size measured by the instrument and so it is likely that aerosol particles at smaller sizes also act as cloud condensation nuclei in this marine environment. As the aircraft approached the transition to a more cumuliform cloud regime (profiles $\mathrm{P} 3$ and P4) both $N_{d}$ and the subcloud $N_{a}$ begin to drop off to values of about $50 \mathrm{~cm}^{-3}$. Later in the flight when the aircraft crossed the transition in cloud morphology (profiles P7 and P8) there is an even sharper reduction in $N_{d}$ and the subcloud $N_{a}$ to values of around $25 \mathrm{~cm}^{-3}$ (see also Fig. 6). The reduction in both $N_{d}$ and $N_{a}$ across the transition in cloud morphology has been observed on other cold-air-outbreak case studies (G. Lloyd et al. 2017, unpublished manuscript) but also from measurements across the transition from overcast stratiform clouds to cumulus clouds in pockets of open cells (POCs) in subtropical stratocumulus regions (e.g., Petters et al. 2006; Sharon et al. 2006; Wood et al. 2008; Terai et al. 2014).
Figure $3 \mathrm{f}$ plots two proxies for ice particle number concentration $N_{i}$. Included are time series of the total number concentration of particles larger than $100 \mu \mathrm{m}$ measured with the CIP-100 and those particles classified as being highly irregular with the 2DS probe. Both measures show that in the stratiform region the values of $N_{i}$ were typically a few per liter, but in the final profile in the convective region (profile P9) there is a marked enhancement of $N_{i}$ to a peak value of $\sim 150 \mathrm{~L}^{-1}$. This is coincident with the peak values measured by the Nevzorov TWC sensor in Fig. $3 \mathrm{c}$ of around $1 \mathrm{~g} \mathrm{~m}^{-3}$. Examination of the aircraft video shows that the cumulus clouds were producing heavy precipitation that reached the sea surface. The rapid enhancement in $N_{i}$ is likely the result of secondary ice processes becoming active. The increase in the precipitation associated with this glaciation of the clouds is also likely to be key in the removal of aerosols from the boundary layer as shown by the reduction in the measured $N_{a}$. This is examined further below.

\section{3) MICROPHYSICS}

\section{(i) Clouds and precipitation}

Figure 4 shows example profiles from the stratiform cloud layer (profile P6) and from the profile in the convective region where the highest $N_{i}$ was measured during the flight (profile P9). The profiles show the ambient temperature, the TWC and LWC measured with the Nevzorov probe, the CIP-100 number concentration (as a proxy for $N_{i}$ ), and illustrative particle imagery from the CIP-100 and 2DS probes. The particle imagery for both profiles is at an ambient temperature of $-7^{\circ} \mathrm{C}$.

The profile of TWC and LWC in the stratiform cloud region shows a cloud base at about $1.1 \mathrm{~km}$ and a cloud top at $1.9-\mathrm{km}$ altitude, which corresponds to temperatures of $-8^{\circ} \mathrm{C}$ at cloud base and $-14^{\circ} \mathrm{C}$ at cloud top. The Nevzorov LWC sensor data is typically within $5 \%$ of the Nevzorov TWC sensor data in the cloud layer, indicating that the cloud water content is dominated by liquid drops. The CDP measurements from this profile show that the volume mean diameter $D_{v}$ of the cloud drops increases from about $10 \mu \mathrm{m}$ at cloud base to about $22 \mu \mathrm{m}$ at cloud top. There is evidence of drizzle and ice particles precipitating beneath the cloud layer as shown in the Nevzorov data and in the particle imagery. The CIP-100 and 2DS instruments indicate that these larger precipitation sized particles are composed of drizzle drops, dendrites, and graupel particles and that they are present in both the cloud and subcloud layers. The dendrites and more heavily rimed graupel particles reach sizes around $2 \mathrm{~mm}$ in diameter. A profile-averaged 
a)

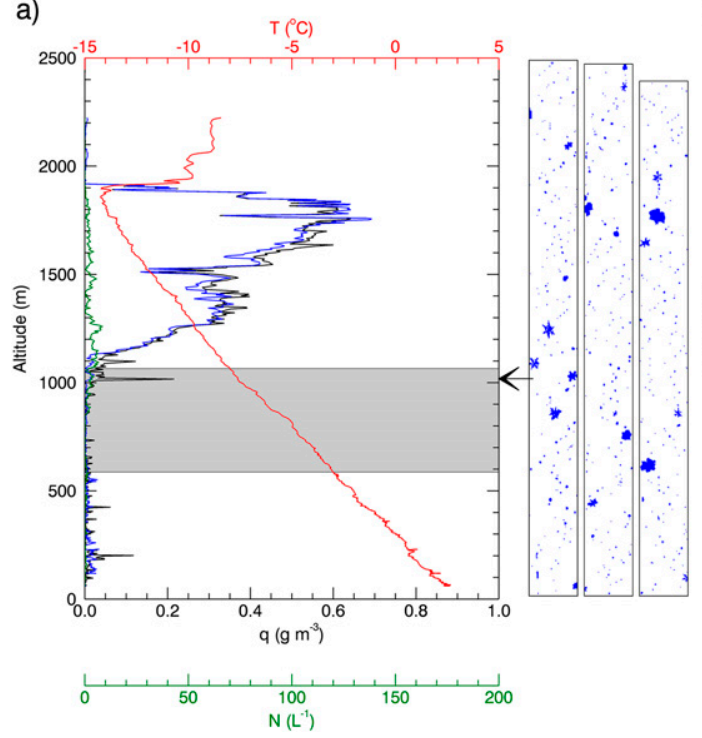

b)

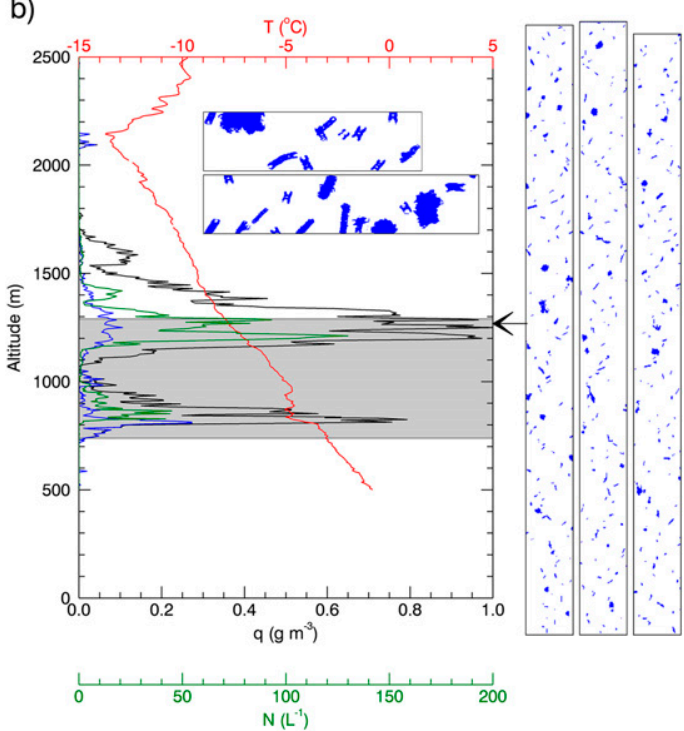

FIG. 4. Example profiles from the (a) stratiform region (P6) and the (b) cumulus region (P9). Profiles show the ambient temperature in red, the TWC (LWC) measured with the Nevzorov in black (blue), and the number concentration of particles larger than $100 \mu \mathrm{m}$ measured with the CIP-100 in green. The temperature zone where the Hallett-Mossop rime-splintering mechanism can occur is shown with gray shading. Beside each profile, representative particle imagery from the CIP-100 at the position of the arrows is shown. The horizontal width of each CIP-100 image strip is $6.4 \mathrm{~mm}$. Example imagery from the 2DS probe highlighting the presence of columns at the same point as the arrow is also shown in (b). The vertical height of each 2DS image strip is $1.28 \mathrm{~mm}$.

composite particle size distribution that combines data from the CDP, 2DS, and CIP-100 probes is shown in Fig. 5 (red symbols). There is a clear mode in the averaged distribution between particle sizes of 10 and $25 \mu \mathrm{m}$ that represents the liquid cloud drops and a tail to the distribution at larger particle sizes that represents the low concentration of precipitation-sized particles.

The profile in the convective region (Fig. 4b) shows two distinct peaks in the TWC and $N_{i}$ from the Nevzorov and the CIP-100 measurements. These include the highest values recorded on the flight and they are located at about $850-\mathrm{m}$ and $1.2-\mathrm{km}$ altitude. The variability in the profile results from the aircraft ascending along a fixed heading through the shallow cumulus clouds, which are horizontally inhomogeneous. The two distinct peaks are likely to be different convective turrets sampled along the aircraft profile. The Nevzorov LWC sensor and the CDP data (not shown) show evidence of smaller amounts of liquid water in these layers. The 2DS and CIP-100 imagery shows that the larger precipitation-sized particles are composed of columnar ice, graupel, and dendrites. There is a significant enhancement in the occurrence of the columnar habits in the regions of increased $N_{i}$. Just below the temperature inversion at the top of the boundary layer there is another small enhancement in the Nevzorov data (2.1-km altitude), which represents a thin tenuous layer of more stratiform cloud (as observed in the aircraft video shown in Fig. S1). This layer is predominantly composed of

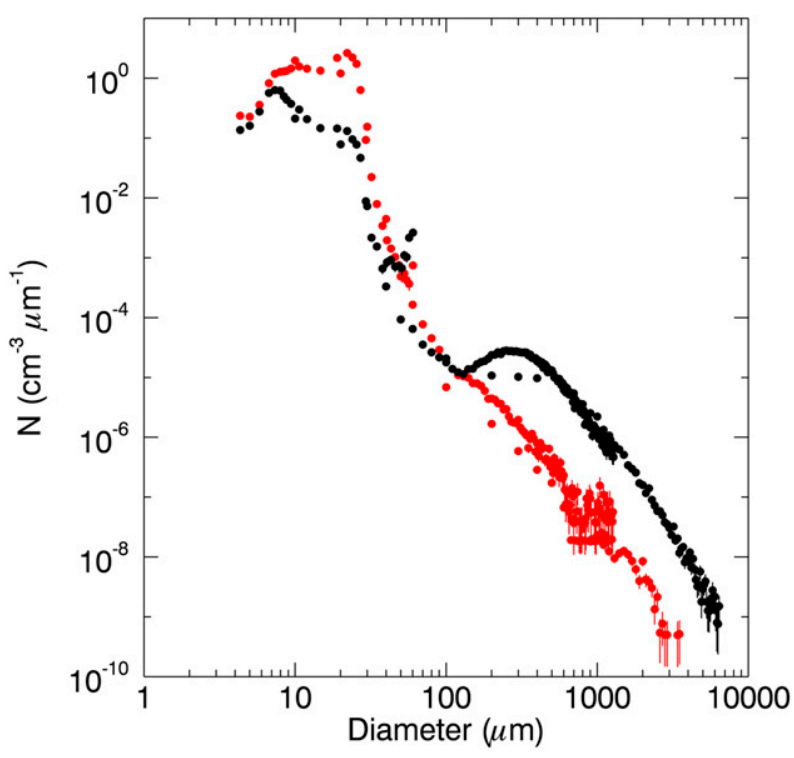

FIG. 5. Size spectra averaged over profiles in the stratiform region (red; P6) and in the convective region (black; P9). Data are from the CDP, 2DS, and CIP-100 probes. Vertical bars on the individual data points represent the Poisson counting error. 
supercooled liquid cloud drops and there is no evidence of ice particles in the 2DS or CIP-100 imagery. The aircraft profiles in the convective region continue to maintain a temperature inversion that was observed to limit the vertical extent of the convective clouds, such that they have similar cloud-top temperatures to the stratiform clouds. The inversion base temperature on profile $\mathrm{P} 9$ for example is at $-14^{\circ} \mathrm{C}$. The thin cloud layer beneath the inversion is likely to be detrained remnants of the cumulus clouds and precipitation of ice (either in the cumulus clouds that formed this layer or before the detrained layer was measured by the aircraft) likely accounts for the absence of ice in the observations. A particle size distribution averaged over profile P9 is shown in Fig. 5 (black symbols). There is a reduction in the concentration of cloud drops $(D<40 \mu \mathrm{m})$ when compared to the data from the profile in the stratiform cloud region and a marked enhancement in the concentration of precipitation sized particles at $D>100 \mu \mathrm{m}$.

The observed enhancement in both $N_{i}$ and ice mass in the shallow cumulus cloud on profile $\mathrm{P} 9$ is consistent with secondary ice formation via the Hallett-Mossop (H-M) mechanism (Hallett and Mossop 1974), whereby numerous ice splinters are produced when supercooled cloud drops accrete and freeze on to the surface of large ice particles such as graupel or snow, both of which were observed in the stratiform and convective cloud regimes. The gray shaded area on the profiles in Fig. 4 spans the temperature range at which the laboratory experiments of Hallett and Mossop (1974) show that the mechanism is active and this is coincident with the observed increase in columnar ice particles on profile $\mathrm{P} 9$. In the stratiform cloud layer (profile P6) the cloud base is higher than in the convective cloud regime and the cloud is therefore located above the $\mathrm{H}-\mathrm{M}$ temperature zone (it is colder). Even though there were rimed graupel particles observed in the stratiform cloud layer, the colder temperatures likely inhibit secondary ice formation via the $\mathrm{H}-\mathrm{M}$ mechanism. Although there were no instruments that measured the concentration of primary ice nucleating aerosol particles (INP) on the aircraft, it is very unlikely that there was an increase in the available INP across the transition in cloud morphology as the convective clouds were directly downwind of the stratiform cloud and therefore in the same maritime air mass (see Fig. 2c). The change in the in-cloud temperature may therefore play a key role in the observed switch from a liquid dominated cloud environment (with low ice concentrations) in the stratiform cloud regime to more glaciated clouds and an enhancement in precipitation in the convective cloud regime.

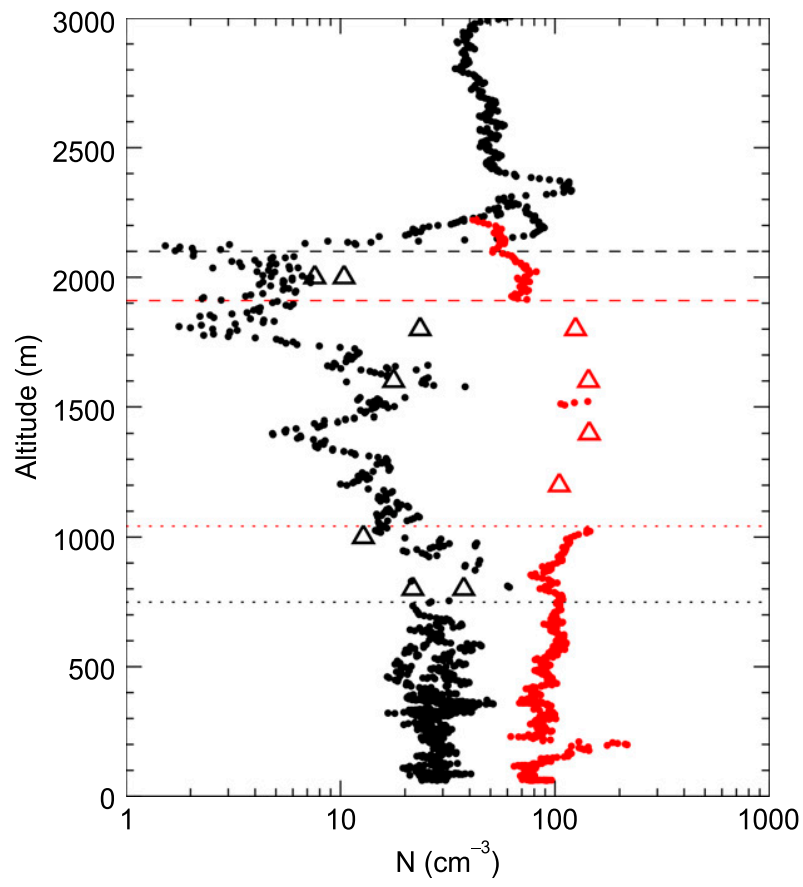

FIG. 6. Profiles of accumulation mode aerosol number concentration measured with the PCASP in the stratiform region (red; P6) and in the convective region (black; P8 and P9). The typical height of the boundary layer inversion base is shown with a dashed line and the cloud base with a dotted line. Mean cloud drop number concentrations from the CDP averaged over 200-m-altitude bins are shown with triangles.

\section{(ii) Aerosols}

Figure 6 shows profiles of the accumulation mode aerosol number concentration measured with the PCASP in the stratiform cloud regime (profile P6) and the convective cloud regime (profiles P8 and P9). Also shown are the cloud-base and cloud-top altitudes and the mean values of the cloud drop number concentration measured with the CDP averaged over 200-m-altitude bins.

There is a marked reduction in the mean subcloud $N_{a}$ across the transition in cloud morphology from $92 \mathrm{~cm}^{-3}$ in the stratiform profile to $28 \mathrm{~cm}^{-3}$ in the convective cloud profiles. This is remarkably consistent with findings in POCs in subtropical marine stratocumulus regions (Terai et al. 2014), which show similar reductions in the subcloud $N_{a}$ from the surrounding overcast cloud into regions of shallow cumulus clouds that also exhibit more vigorous precipitation. For the five cases examined by Terai et al. (2014), the subcloud $N_{a}$ within the POC region varied over a narrow range of $24-40 \mathrm{~cm}^{-3}$. The reduction in the subcloud $N_{a}$ is also coincident with a marked reduction in the mean in-cloud $N_{d}$ across the transition, from $118 \mathrm{~cm}^{-3}$ in the stratiform region (profile P6) to $19 \mathrm{~cm}^{-3}$ in the convective region 

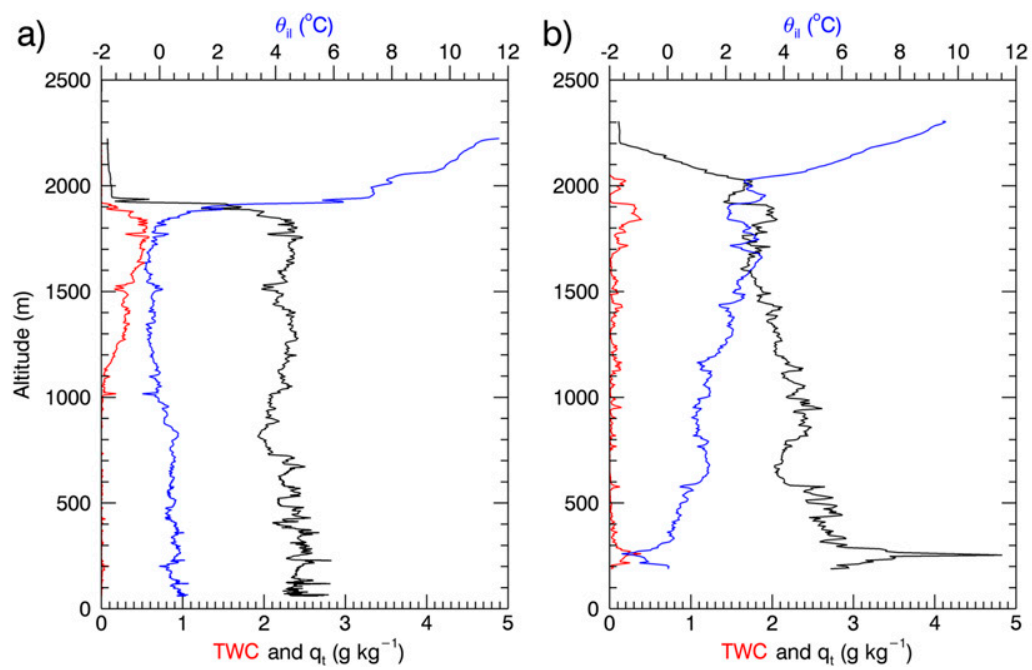

c)

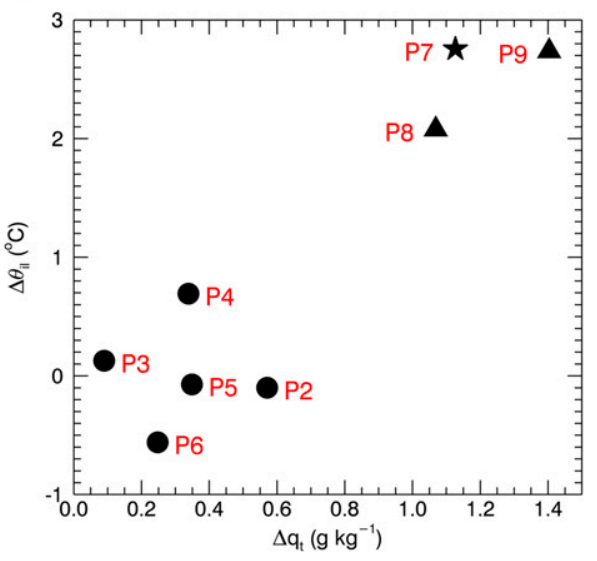

FIG. 7. Example profiles of $q_{t}$ measured by the total water probe, TWC measured with the Nevzorov probe and ice-liquid potential temperature $\theta_{\text {il }}$ for the (a) stratiform region (profile P6) and the (b) transition region (profile P7). (c) Boundary layer decoupling metrics $\Delta q_{t}$ vs $\Delta \theta_{\text {il }}$ for profiles $\mathrm{P} 2-\mathrm{P}$ 9. The circles are profiles in the stratiform cloud region, triangles in the convective cloud regime, and the star at the transition.

(profiles $\mathrm{P} 8$ and $\mathrm{P} 9$ ). This marked reduction in both $N_{a}$ and $N_{d}$ in the convective cloud regime suggests a rapid removal of aerosols from in-cloud collision-coalescence processes and subsequent precipitation.

Another consistent feature in the profile of $N_{a}$ found in the convective cloud regime from this cold-airoutbreak case and from the previous observations from POCs in Terai et al. (2014) is the presence of an ultraclean layer beneath the inversion at the top of the marine boundary layer. Figure 6 shows that in this layer the $N_{a}$ drops off to values of a few per cubic centimeter and the cloud that does form in this layer has $N_{d}<$ $10 \mathrm{~cm}^{-3}$. As discussed previously, this cloud exhibits different features from the more glaciated actively growing cells in the convective region, being predominantly composed of liquid drops and exhibiting a more stratiform cloud appearance. Finally, it is evident that directly above the inversion at the top of the marine boundary layer $N_{a}$ in the stratiform cloud and convective cloud regimes are similar. The above-inversion $N_{a}$ is significantly higher than the $N_{a}$ measured in the ultraclean layer directly below the inversion in the convective cloud regime, suggesting that entrainment of freetropospheric aerosols into the cloud layer plays a limited role in controlling the cloud microphysics.

\section{4) BOUNDARY LAYER STRUCTURE}

Figure 7 examines the change in the boundary layer structure across the transition in cloud morphology. Example measurements of the $q_{t}$ measured with the total water probe, the Nevzorov total condensed water content and measurements of the ice-liquid water potential temperature $\theta_{\mathrm{il}}$ are shown from a profile in the stratiform region (profile $\mathrm{P} 6$ ) and from a profile in the area where the cloud begins to break up (profile P7). Although the midpoint of profile $\mathrm{P} 7$ is only about $85 \mathrm{~km}$ downwind from the midpoint of profile P6 (see Fig. 2), there is a marked change in the boundary layer structure between these profiles. The mean boundary layer wind speed is $15 \mathrm{~m} \mathrm{~s}^{-1}$, which suggests that this change had occurred in less than $2 \mathrm{~h}$ along the boundary layer flow. Profile P6 shows a classic well-mixed stratocumulustopped boundary layer, in which the turbulence mixes the moist conserved variables $q_{t}$ and $\theta_{\text {il }}$ throughout the depth of the boundary layer. There are strong and vertically thin $(\sim 50 \mathrm{~m})$ inversions in both moisture and temperature at the top of the boundary layer. The condensed water content in the cloud layer exhibits a linear increase from cloud base at about $1.1 \mathrm{~km}$ to the height of the inversion base at about $1.9 \mathrm{~km}$. Downwind at profile P7, there are noticeable gradients in the boundary layer profiles of both $q_{t}$ and $\theta_{\mathrm{il}}$, indicating that the turbulence is not able to maintain a well-mixed layer throughout the entire depth of the boundary layer. For example, there is an increase in the water vapor content and a reduction in $\theta_{\text {il }}$ at low levels as compared to the profile in the wellmixed boundary layer upwind. Visual inspection from the aircraft video also shows evidence of shallow cumulus clouds rising into the overlying stratocumulus cloud deck when approaching the transition on profile P7, indicating a lowering in the cloud base. The height of the base of the inversion has risen by about $125 \mathrm{~m}$ from profile P6 to profile P7 and the depth of the inversion layer has increased to about $200 \mathrm{~m}$, as inferred from the 
altitude at which the profile of $q_{t}$ reaches values more typical of the free troposphere. This would be consistent with the shallow cumulus observed on profile P7 more actively mixing air from the free troposphere into the boundary layer. The Nevzorov TWC measurements from profile $\mathrm{P} 7$ show that the peak liquid water contents immediately beneath the inversion have been depleted and that there is clear evidence of enhanced precipitation close to the surface when compared to the upwind profile. The observations of enhanced precipitation and of a cooling and moistening of the subcloud layer are consistent with the idea that the boundary layer becomes decoupled as a direct result of the evaporation of hydrometeors, which has been shown in modeling and observational studies to lead to similar transitions in cloud morphology in subtropical stratocumulus-topped boundary layers (e.g., SavicJovcic and Stevens 2008; Terai et al. 2014).

The boundary layer structure from all of the measured profiles is characterized in Fig. $7 \mathrm{c}$ using the metric of Jones et al. (2011). This metric broadly quantifies the gradient in $q_{t}$ and $\theta_{\text {il }}$ through the boundary layer. We calculate $\Delta q_{t}=q_{t, \text { bottom }}-q_{t, \text { top }}$ and $\Delta \theta_{\text {il }}=\theta_{\text {il,top }}-\theta_{\text {il,bottom }}$, where the subscripts "bottom" and "top" denote the mean of the measured variable over the lowest and uppermost $25 \%$ of the boundary layer depth beneath the inversion. A profile that is well mixed would therefore have values of $\Delta q_{t}$ and $\Delta \theta_{\mathrm{il}}$ close to zero. Profile $\mathrm{P} 1$ is not included as there were no measurements made below $1160 \mathrm{~m}$ above the sea surface. There is a clear separation between those profiles in the overcast stratiform cloud deck (profiles P2-P6), which exhibit values of $\Delta q_{t}<$ $0.6 \mathrm{~g} \mathrm{~kg}^{-1}$ and $\Delta \theta_{\mathrm{il}}<0.7^{\circ} \mathrm{C}$ and those profiles located at the boundary to or within the convective cloud regime (profiles P7-P9), which all have values of $\Delta q_{t}>1 \mathrm{~g} \mathrm{~kg}^{-1}$ and $\Delta \theta_{\mathrm{il}}>2^{\circ} \mathrm{C}$. It is clear that a marked shift in the boundary layer structure therefore occurs between the two cloud regimes.

We also calculate the cloud-top entrainment instability parameter $\kappa$ of Lock (2009) for all of the observed profiles. This parameter examines the changes in temperature and moisture across the capping inversion to give a measure of the buoyancy of air parcels that form from mixtures of cloudy air and entrained freetropospheric air. Values of $\kappa>0.2$ are indicative of a regime where the entrainment at cloud top is conducive to generating negatively buoyant mixtures that sink away from cloud top, which act to further enhance entrainment rates, promoting a breakup of the stratiform cloud layer. For values of $\kappa<0.2$, negatively buoyant mixtures are not prevalent and the cloud tends to remain overcast. From the observations, we calculate $\kappa$ using the change in $\theta_{l}$ and $q_{t}$ between the inversion base and a level above the cloud where the value of $q_{t}$ is representative of the free-tropospheric value. The calculated $\kappa$ was 0 or less for all of the observed profiles, both in the stratiform and convective cloud regimes. This suggests that the cloud-top entrainment instability feedback is not the key driver for the breakup of the stratocumulus cloud layer in this cold-air outbreak.

\section{b. Model simulations}

In this section we present model simulations of the case study and compare them against the observations. We also utilize the model simulations to further investigate the mechanisms responsible for the breakup of the stratocumulus cloud layer.

\section{1) Cloud PROPERTIES}

Figure 8 shows the low-level cloud fraction and LWP at 1200 UTC from the control model simulation. This can be compared to the MSG visible imagery and AMSR2 satellite data in Fig. 2. The model is able to capture many of the salient features of the cloud macrostructure. The model simulates the stratiform cloud cover to the north of the $70^{\circ} \mathrm{N}$ latitude line and the strip of overcast cloud close to the $0^{\circ}$ meridian that extends southward over the operating area of the aircraft. The model also captures the breakup of the cloud layer into cumulus clouds toward the eastern edge of the aircraft flight track. However, the model clearly underestimates the LWP values in the stratiform cloud region. The peak LWP values from the simulation are $\sim 100 \mathrm{~g} \mathrm{~m}^{-2}$. This is significantly lower than both the AMSR2 satellite and the in situ airborne measurements that show LWP values of $\sim 300-400 \mathrm{~g} \mathrm{~m}^{-2}$. This significant underestimate of the LWP in the control model simulation and the evidence from the aircraft observations that precipitation increases across the transition in cloud regimes, motivated a series of sensitivity tests to be performed:

- Modified ice: This simulation modifies the ice cloud fraction parameterization as detailed in the appendix. The modification aims to limit the overlap between ice and liquid water in the model grid box, as even on kilometer scales ice and liquid are not homogeneously mixed (Tan and Storelvmo 2016). Furtado and Field (2017) have shown that in the UM the riming of liquid water onto ice particles in mixed-phase boundary layer clouds is a very effective mechanism for removing liquid water from the cloud layer. By limiting the ice cloud fraction, such that regions of liquid water in the cloud are shielded from the ice, we expect there to be a subsequent increase in cloud LWP.

- No ice: This experiment converts all ice from the initial and boundary conditions into liquid water 
a)

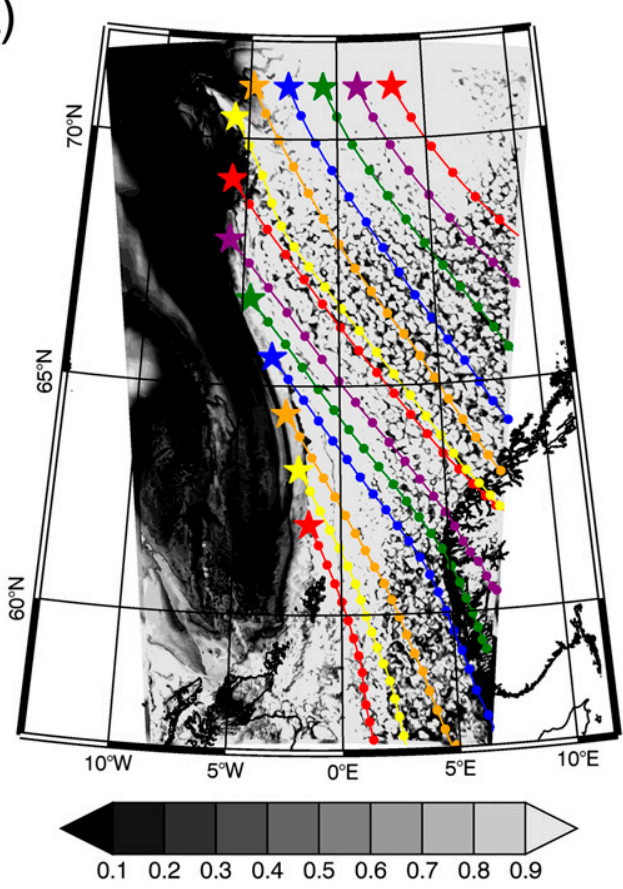

b)

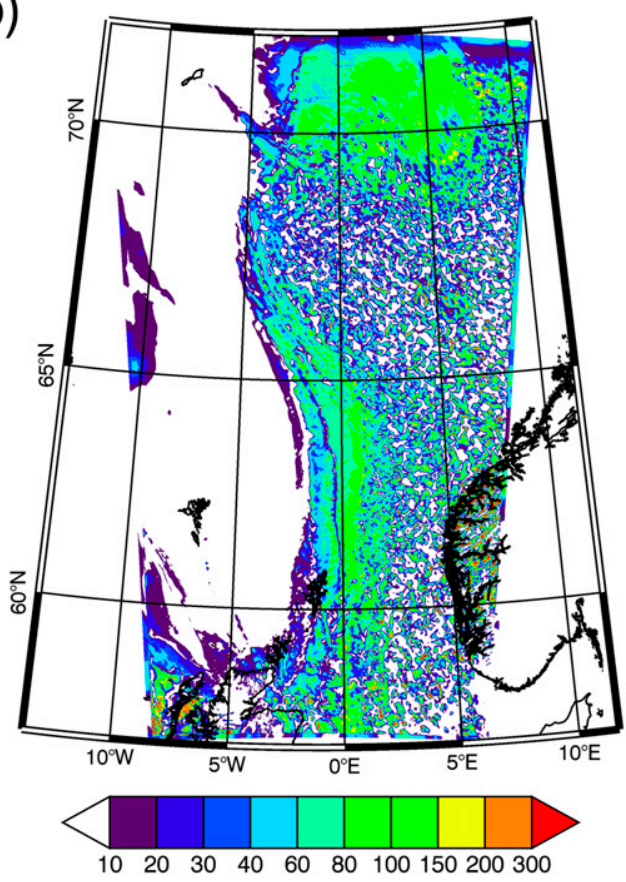

FIG. 8. (a) Low-level cloud fraction from the control model at 1200 UTC with a subset of the trajectories initialized at 0300 UTC overlaid. The starting points of the trajectories are indicated with a star and hourly time points along each trajectory are shown with filled circles. (b) LWP $\left(\mathrm{g} \mathrm{m}^{-2}\right)$ from the control model at 1200 UTC.

(including a latent heat correction). The temperature for homogeneous and heterogeneous ice nucleation is also set to $-100^{\circ} \mathrm{C}$ to prevent any ice from forming during the simulation. The aim of this experiment is to determine what effect ice processes have on the stratiform cloud properties and the subsequent transition into cumulus clouds.

- Enhanced warm rain: This experiment is based on the no-ice simulation. The autoconversion rate is enhanced by a factor of 10 to speed up the warm-rain creation process. The aim of this experiment is to examine the impact of increasing the rate of precipitation formation on the cloud properties and breakup.

- No precipitation: This experiment is based on the noice simulation, but the creation of warm rain is prevented by setting the autoconversion rate to zero. The aim of this simulation is to isolate the impact that both ice- and liquid-phase precipitation have on the cloud breakup.

Figure 9 gives a visual representation of the cloud field around the aircraft flight track from the MSG visible satellite data (as in Fig. 3) and from the model simulations. The model data in Figs. 9b-f show the upwelling shortwave flux at the top of the atmosphere normalized by the reciprocal of the cosine of the solar zenith angle (SZA). The normalization is applied because the solar zenith angle is close to the horizon and is changing rapidly during this time period (from $88^{\circ}$ to $81^{\circ}$ ). The model data are updated every $15 \mathrm{~min}$ to be coincident with the satellite and aircraft observations. It is clear that there are biases in the cloud regime simulated by the control model when focusing in on the region of the aircraft operations. The model generally exhibits a more broken cloud field when the aircraft flew in the overcast stratocumulus cloud deck (1000-1100 UTC) and breaks this up into shallow cumulus clouds farther west than in reality; that is, it occurs earlier in Fig. 9 as the aircraft flew eastward across the transition at about 1100 UTC. The modified-ice simulation results in a more overcast cloud field in the stratiform region and delays the onset of the transition to convective clouds slightly. This trend is amplified in the simulation where no ice processes are active, with the model simulation leading to an almost completely overcast cloud field in the area of the aircraft operations, even when the aircraft had crossed over into the convective cloud regime. This suggests that the ice processes in the model are playing an important role in the breakup of the cloud field. The enhanced-warm-rain simulation looks more similar to the modified-ice simulation. When compared to the no-ice simulation on which it is based, this suggests that it is precipitation processes themselves (liquid or ice phase) that modify the timing of the breakup in the model. This is supported 


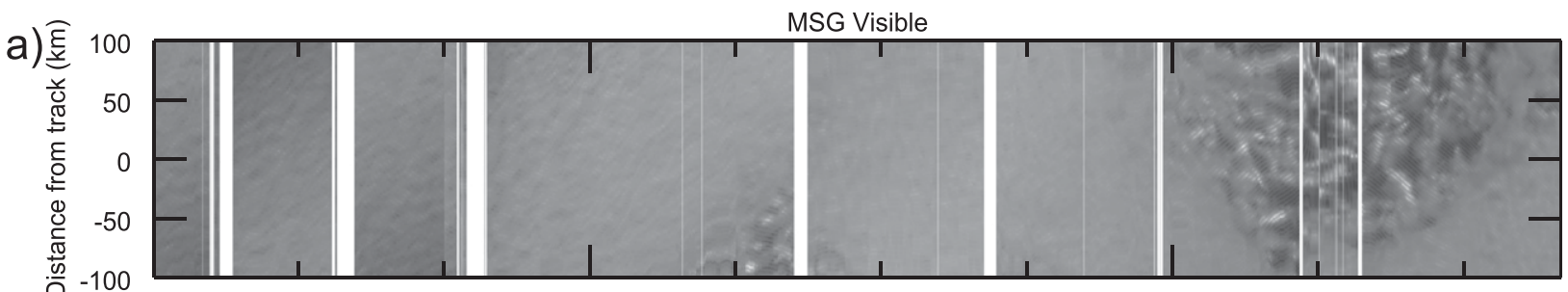

b) $\bar{\xi} 100$ Control

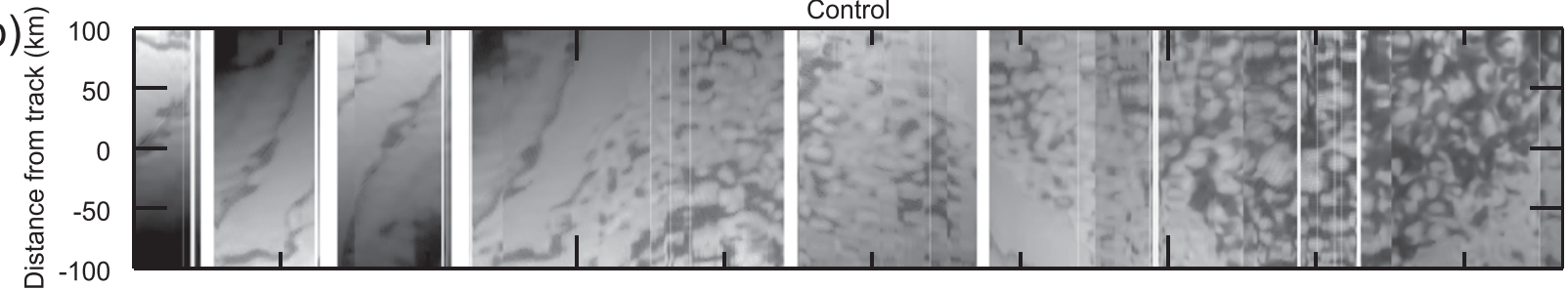

c) $\widehat{\widehat{\xi}} 100$

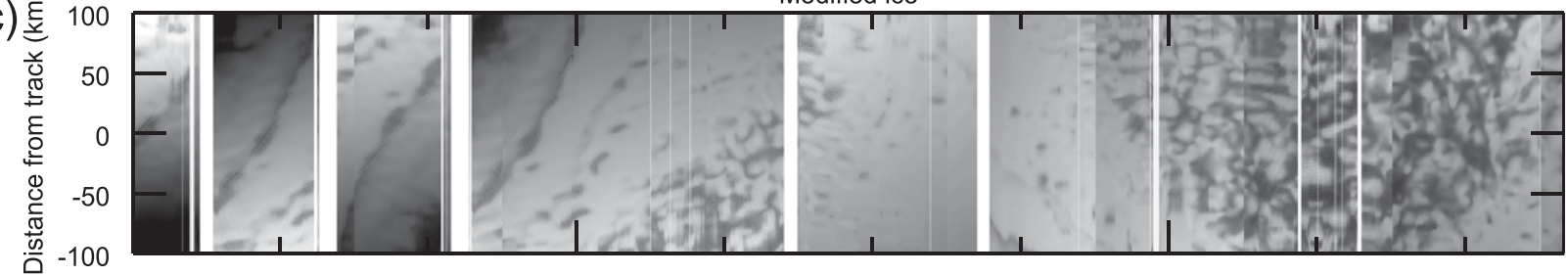

d) $\underset{\frac{\xi}{\Sigma}}{\frac{E}{g}} 100$ No ice

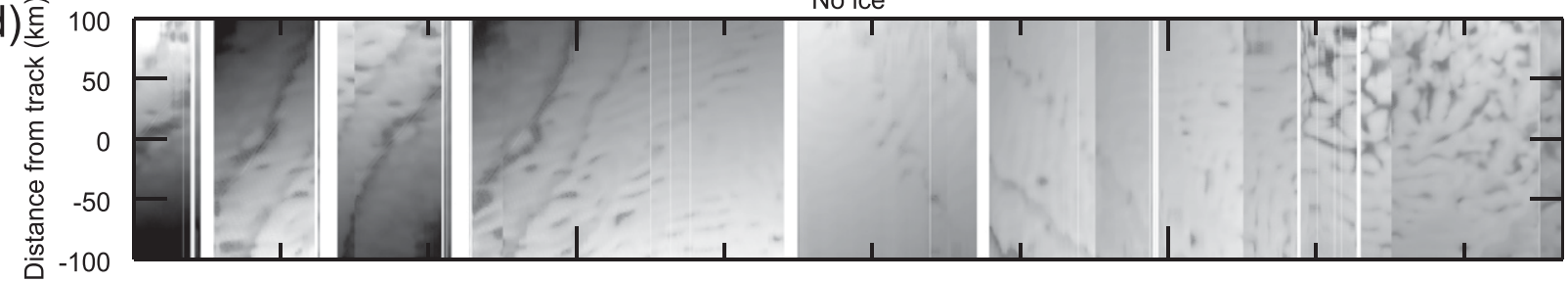

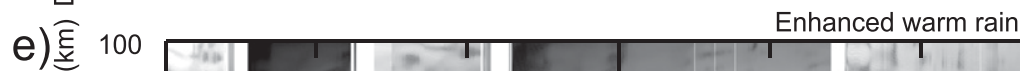

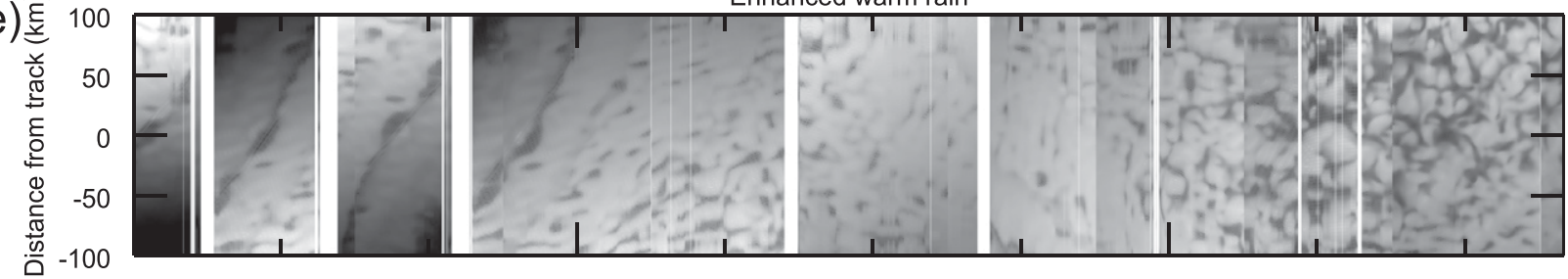

f) $\widehat{\xi} 100 \quad$ No precipitation

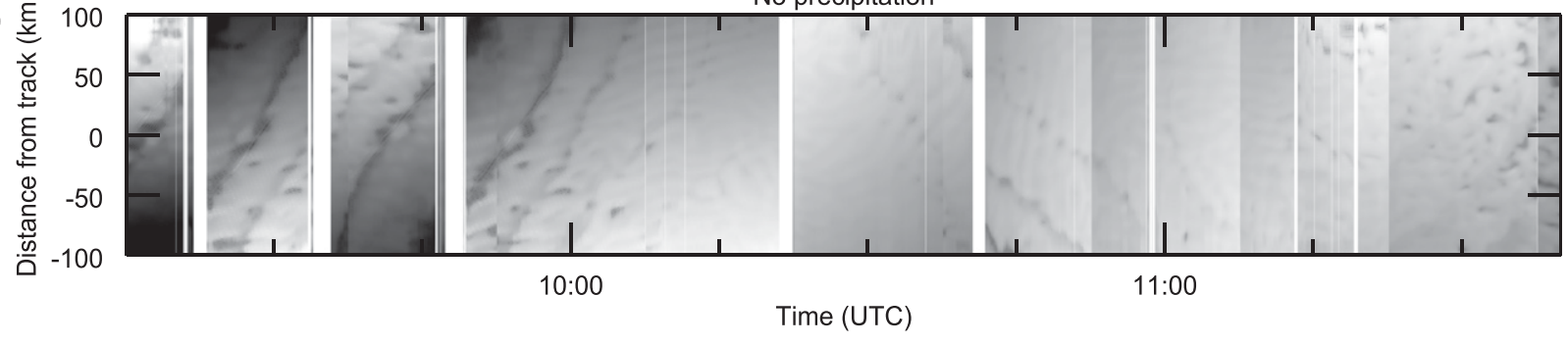

FIG. 9. Time series showing the cloud field around the aircraft flight track. (a) MSG visible imagery as a function of distance from the track. Above (below) the zero line is the view to the left (right) of the aircraft. Data during aircraft turns are blanked out. (b)-(f) Corresponding outgoing shortwave flux at the top of the atmosphere normalized by $1 / \cos (\mathrm{SZA})$ from the model simulations.

further by the results from the no-precipitation simulation, which exhibits no breakup of the cloud field. The role that precipitation plays in modulating the cloud morphology will be explored further in section $4 \mathrm{~b}(2)$.
Figure 10 plots the model LWP data along the flight track and compares it with the aircraft measurements. This again shows the significant low bias of LWP in the control model simulation, with typical values in the 


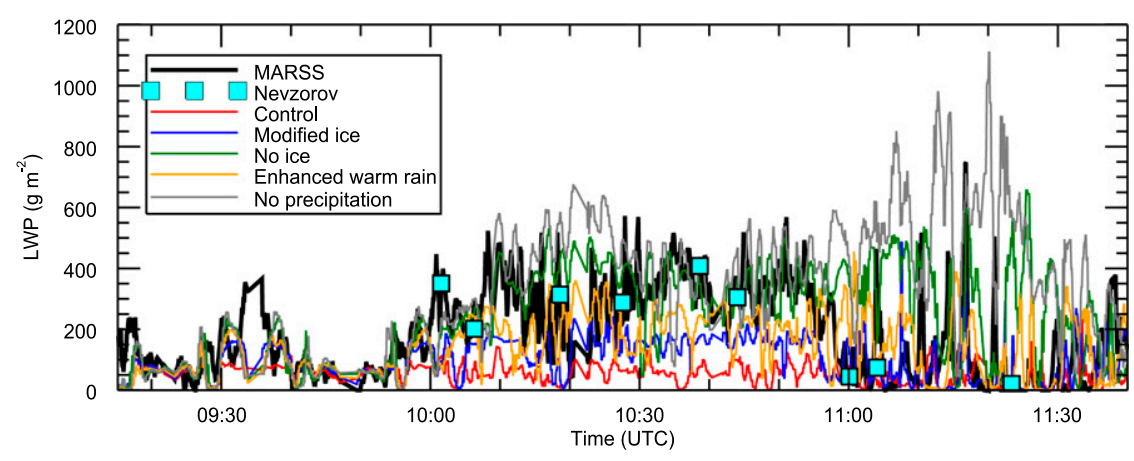

FIG. 10. Time series of liquid water path along the flight track from the model simulations and the observed values from the MARSS instrument and the Nevzorov probe.

stratiform cloud region being a factor of 4 lower than the observations. The modified-ice simulation increases the simulated LWP by about a factor of 2 , but it is only when no ice processes are active that the model is able to simulate values that are comparable to reality in the stratiform cloud region. This indicates that the warmrain precipitation efficiency of the model in stratocumulus clouds in this marine environment does not exhibit a large bias. However, the no-ice experiment overestimates LWP in the observed convective cloud regime because it maintains a more overcast cloud field. The same is true for the no-precipitation simulation, which exhibits even higher LWP values. The enhancedwarm-rain simulation lies in between the no-ice and modified-ice simulations. The large variability in the simulated LWP from the different model simulations is highlighted further in Fig. 11a, which presents a histogram of the observed and modeled LWP data along the flight track.

Also included in Fig. 11 are example profiles in the stratocumulus cloud regime of LWC, liquid cloud fraction, and ice cloud fraction. The location of the data is at the midpoint of profile P6 in the aircraft observations. This profile was chosen as all of the model simulations have a low-level cloud fraction of 1.0 in a $10.5 \mathrm{~km} \times$ $10.5 \mathrm{~km}$ box surrounding that point. The model profiles of LWC from all of the simulations show a realistic shape to the profile, with values increasing from cloud base to cloud top. The difference in the peak LWC values are in accordance with the difference shown in LWP, such that only the no-ice and no-precipitation model runs exhibit cloud-top LWC values that are similar to the observations. All of the model runs exhibit a low bias in cloud-top height of $\sim 100 \mathrm{~m}$, which is likely in part due to the vertical resolution of the model that has layer thicknesses of about $160 \mathrm{~m}$ at this altitude. The liquid and ice cloud fraction plots demonstrate that in the control model simulation, the model simulates an almost completely homogeneous mixture of ice and liquid in the cloud layer. This results in a marked lowering in the model LWC (as compared to the no-ice simulation) by both vapor deposition and riming of liquid water onto the ice particles in the cloud. The modified-ice simulation reduces the ice cloud fraction significantly in the cloud layer so that there are significant regions in the grid box where liquid water is shielded from the ice. This allows higher gridbox liquid cloud fraction values and larger mean LWCs to exist than in the control simulation.

\section{2) TRAJECTORY ANALYSIS}

The aircraft observations have provided evidence of a marked change in the cloud, precipitation, and boundary layer structure across the transition from the stratiform cloud deck to a more cumuliform cloud regime. To examine the processes that coincide with this breakup of the cloud in the model simulations, we run pseudoLagrangian trajectories through the model domain that follow the air mass in the marine boundary layer. Trajectories are initialized hourly at a series of 25 start points upwind of the breakup region. The mean wind speed and direction below $1.5-\mathrm{km}$ altitude and averaged over a $10.5 \mathrm{~km} \times 10.5 \mathrm{~km}$ box surrounding the trajectory midpoint is used to advect the trajectory along the flow at a time step of $15 \mathrm{~min}$. This results in several hundred trajectories for each model simulation and a subset of these from the control model are shown in Fig. 8. The model wind vectors are in good agreement with the aircraft observations as shown in Fig. 2c.

Figure 12 contours vertical profiles of cloud LWC, precipitation rate, and $q_{t}$ as a function of time along an example trajectory from the control model simulation. The trajectory crosses through the center of the aircraft operating region at about 1045 UTC. At the beginning of the trajectory (before 0800 UTC) the model simulates a stratocumulus-topped boundary layer with cloud tops at about $1.9-\mathrm{km}$ altitude. There is evidence of precipitation below the cloud base at rates between 0.5 and $1 \mathrm{~mm} \mathrm{~h}^{-1}$. 
a)
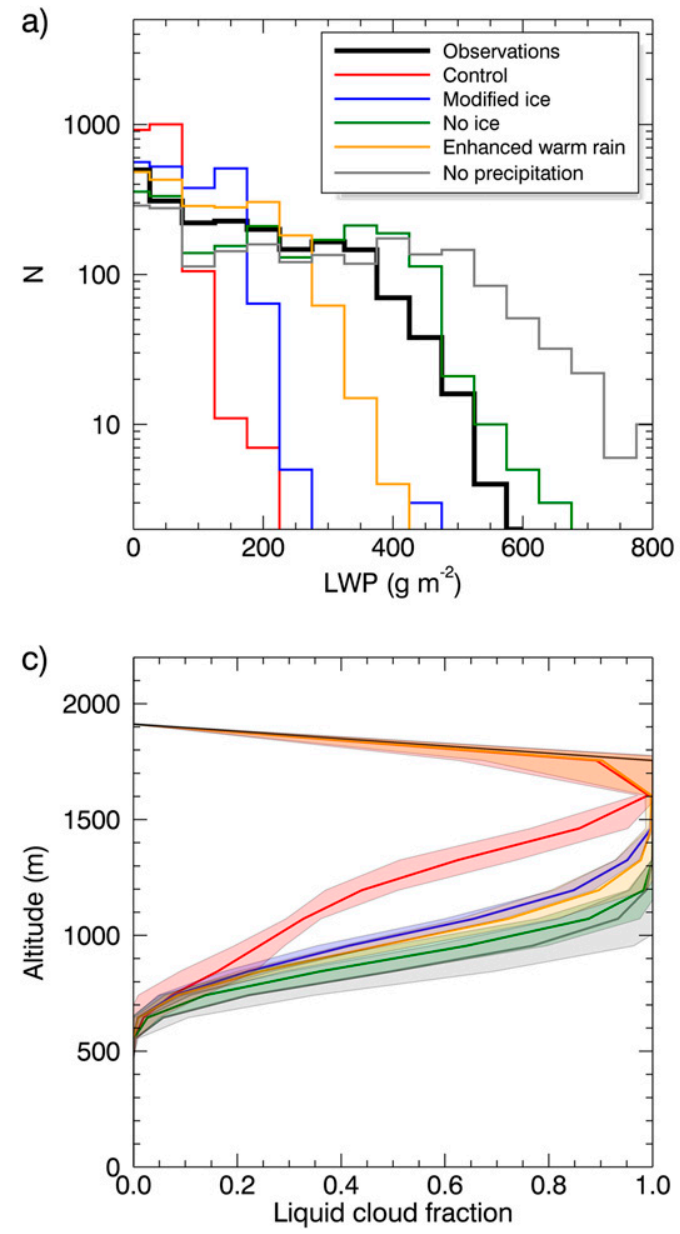

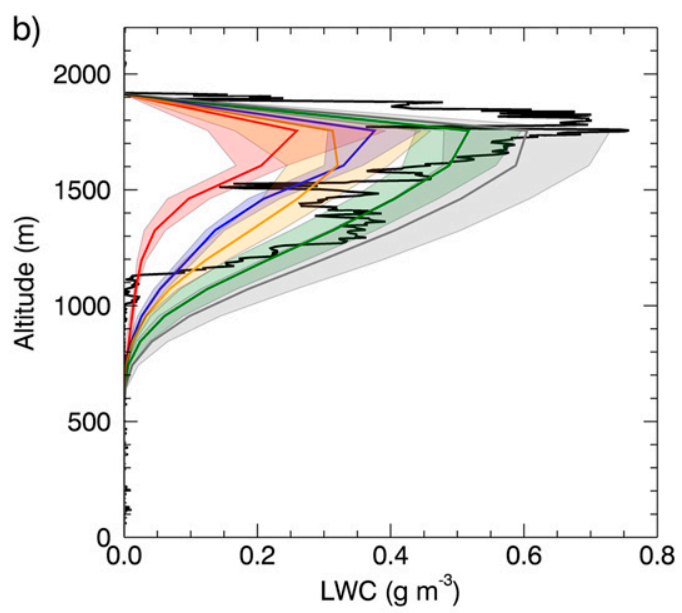

d)

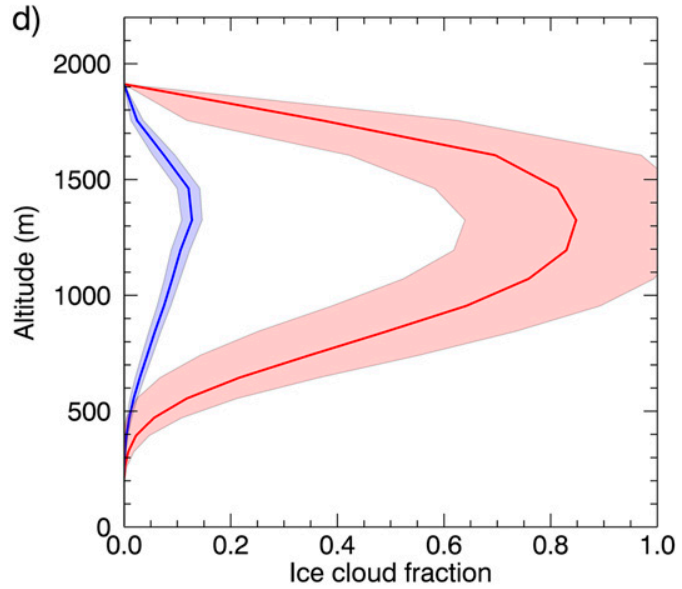

FIG. 11. (a) Histogram of LWP data along the flight track. Observations from the MARSS instrument are shown in black and the model runs in red (control), blue (modified ice), green (no ice), orange (enhanced warm rain), and gray (no precipitation). (b)-(d) Example profiles of LWC, liquid cloud fraction, and ice cloud fraction from the stratiform region (profile P6). Data from the Nevzorov instrument is shown in black in (b) and the model simulations use colors as in (a). The solid lines for the model data are the mean profile in a $10.5 \mathrm{~km} \times 10.5 \mathrm{~km}$ box centered on the observation and the shading represents plus and minus one standard deviation.

This is predominantly ice-phase precipitation in the control model and it evaporates before reaching the sea surface. This does lead to a slight moistening of the subcloud layer as seen in the profile of $q_{t}$, although the boundary layer remains fairly well mixed with the decoupling metric $\Delta q_{t}<0.6 \mathrm{~g} \mathrm{~kg}^{-1}$, in broad agreement with the aircraft observations in the stratiform region presented in Fig. 7. The peak cloud LWC value in this cloud layer is $0.33 \mathrm{~g} \mathrm{~m}^{-3}$, which is lower than typical observed values in the stratiform region but comparable to the maximum value from the control model shown in the example profile in Fig. 11b.

Between about 0900 and 1300 UTC the boundary layer deepens by about $100 \mathrm{~m}$ with cloud tops rising to about $2-\mathrm{km}$ altitude. There is evidence of a significant increase in precipitation with peak values in the precipitating cells exceeding $5 \mathrm{~mm} \mathrm{~h}^{-1}$. The evaporation of the heavier precipitation results in a significant moistening of the subcloud layer, with the $2.25 \mathrm{~g} \mathrm{~kg}^{-1} q_{t}$ contour extending up to a similar altitude as the stratocumulus cloud base and near-surface values of $q_{t}$ increasing to about $3.5 \mathrm{~g} \mathrm{~kg}^{-1}$. Shallow cumulus clouds are also concurrent with this region of enhanced precipitation. The LWC data indicate typical cloud bases of about 500-m altitude and that the shallow cumulus clouds are rising into the overlaying stratiform cloud deck at 1000 UTC. The presence of these shallow cumulus clouds highlights that the stratiform cloud layer has become decoupled from the surface moisture fluxes. This is consistent with the aircraft observations across the transition in cloud regimes measured during profile P7. 


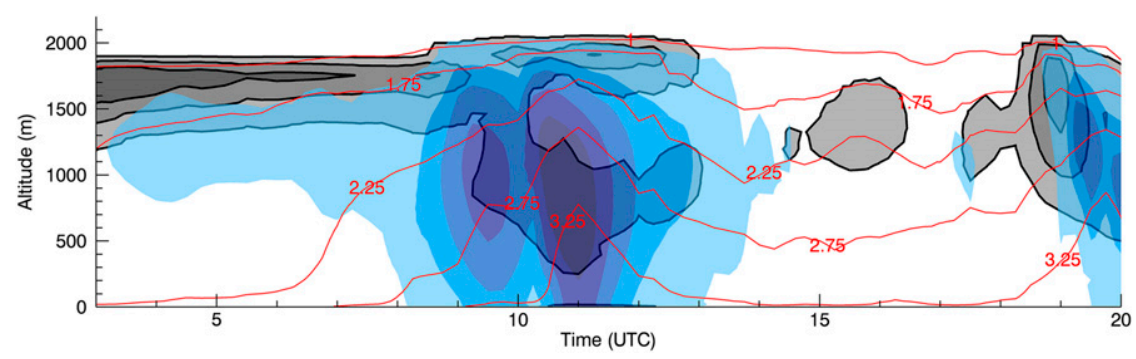

FIG. 12. Example data from a model trajectory in the control simulation that passes through the area of operation covered by the aircraft measurements. Data included are cloud LWC (light to dark gray shading indicates $0.02,0.1$ and $0.2 \mathrm{~g} \mathrm{~m}^{-3}$ ), precipitation rate (light to dark blue shading indicates $0.5,2,3,4$, and $5 \mathrm{~mm} \mathrm{~h}^{-1}$ ), and $q_{t}$ in red contours (at 1, 1.75, 2.25, 2.75, and $3.25 \mathrm{~g} \mathrm{~kg}^{-1}$ ). LWC and $q_{t}$ are averaged values from a $10.5 \mathrm{~km} \times 10.5 \mathrm{~km}$ box surrounding the trajectory and the precipitation rate the peak value within that box.

From 1300 UTC onward the overlying stratiform cloud layer has dissipated and there are intermittent shallow cumulus clouds along the trajectory that continue to form precipitation that reaches the sea surface. The moistening of the subcloud layer from the heavy precipitating cells in the transition region has resulted in the boundary layer remaining decoupled, with a significant reduction in $q_{t}$ with altitude from the sea surface to top of the marine boundary layer. This is again broadly consistent with the aircraft observations in the convective cloud regime shown in Figs. 4 and 7.

A composite analysis of the model trajectories is performed by identifying those trajectories that cross a breakup in the stratiform cloud deck and then analyzing data along those trajectories relative to the transition. A series of tests are used to define when a trajectory crosses the transition. Low-level cloud fraction data are averaged over a $31.5 \mathrm{~km} \times 31.5 \mathrm{~km}$ box centered on the trajectory and a test is performed to see when this drops below 0.95 . The size of the box was selected to discriminate between the stratiform cloud and convective cloud cells in the model, as many of the convective cloud cells in the model simulations span horizontal extents of several tens of kilometers (see Fig. 9). A second check is then performed to ensure that the low-level cloud fraction is larger than 0.95 for the preceding $4 \mathrm{~h}$, although single 15-min time points that drop below this threshold are allowed. This resulted in the identification of 155 , 158,117 , and 155 trajectories that crossed a transition for the control, modified-ice, no-ice, and enhanced-warmrain simulations. The lower number in the no-ice simulation is due to the increased persistence of the stratiform cloud layer in that simulation. The no-precipitation simulation did not exhibit any appreciable changes in cloud regime. A few transitions were detected using the above definition, but not enough to perform a composite analysis. These transitions tended to be located close to the Norwegian coastline or downwind of the
Shetland Islands, suggesting that the flow over and around elevated topography may also play a localized role in modulating the cloud field.

Figure 13 shows a series of variables from the control model simulation plotted as a function of time relative to the transition. Included are the median and interquartile range from all of the trajectories that were identified to cross a transition. By design, the model low-level cloud fraction in Fig. 13a shows overcast conditions before the transition and a reduction in cloud cover afterward. Where available, data from the aircraft profiles are overplotted. The times relative to the transition for the aircraft data are estimated by running model trajectories from the position and time of each profile. The trajectories are then compared to the MSG satellite imagery in order to visually identify when the trajectory crosses from a stratiform to cumulus cloud field. It is estimated that there is an error of about $\pm 1 \mathrm{~h}$ in this method.

Figure 13b shows a gradual increase in sea surface temperature (SST) along the trajectories, which has been shown to be fundamental to the breakup of stratocumulus clouds in the subtropics (Sandu et al. 2010; Sandu and Stevens 2011). The conceptual model of Bretherton and Wyant (1997) links the warming SST in the subtropics to increases in the surface latent heat flux, which in turn acts to enhance buoyancy in the cloud layer faster than in the subcloud layer, promoting boundary layer decoupling and a subsequent breakup of the stratocumulus cloud. Figure $13 \mathrm{c}$ shows that in these model simulations there is no clear increase in the surface latent heat flux as the air mass is advected over the warmer SST in these cold-air-outbreak conditions. The expected increase in the latent heat flux from the conceptual model may be suppressed by the increase in the near-surface water vapor content from the evaporation of increasing amounts of precipitation along the trajectories (e.g., Fig. 12). The model does exhibit a gradual reduction in the surface sensible heat fluxes along the 
a)

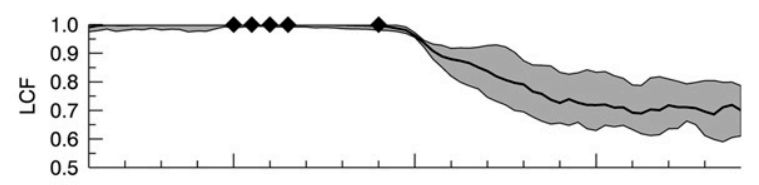

b) 0

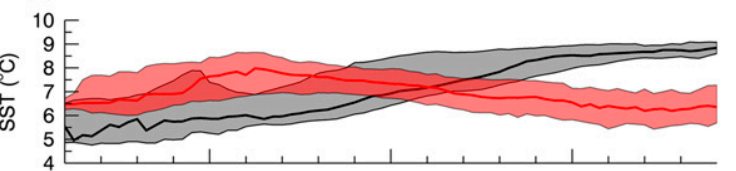

c)

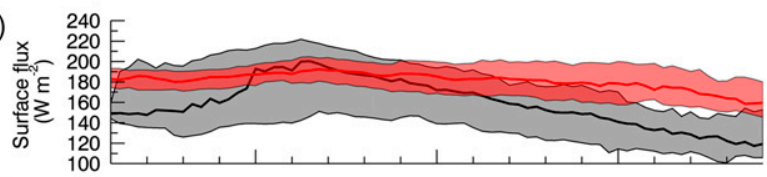

d)

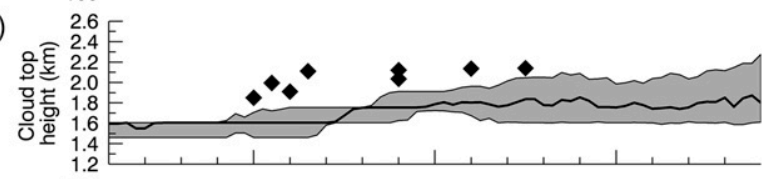

e)

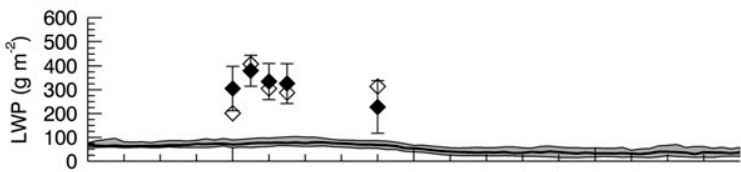

f)

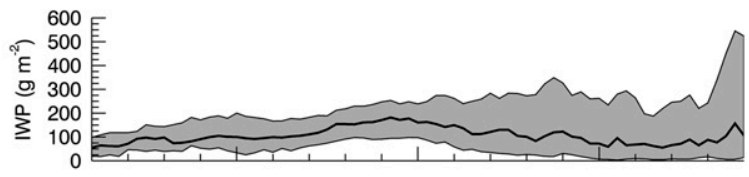

g)

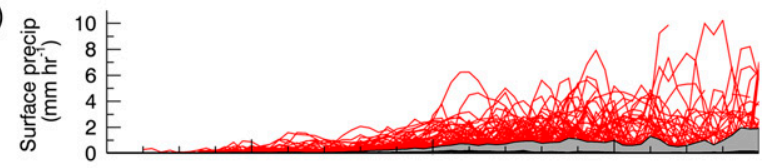

h)

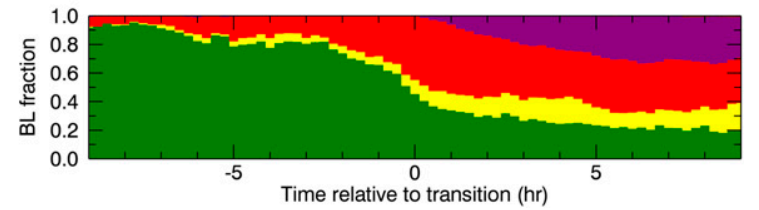

FIG. 13. Model trajectories from the control simulation plotted relative to the transition in low-level cloud fraction. (a) Low-level cloud fraction, (b) sea surface temperature (gray) and the sea surface temperature minus 5-m air temperature (red), (c) surface sensible (gray) and latent (red) heat fluxes, (d) cloud-top height, (e) LWP, (f) IWP, (g) surface precipitation rate, and (h) the fraction of boundary layer types identified as being well mixed (green), decoupled stratocumulus (yellow), decoupled stratocumulus with cumulus below (red), or cumulus capped (purple). Data from the individual trajectories are averaged over a $10.5 \mathrm{~km} \times 10.5 \mathrm{~km}$ box, except for precipitation rate, which uses the peak value and lowlevel cloud fraction that is averaged over a $31.5 \mathrm{~km} \times 31.5 \mathrm{~km}$ box. In (a)-(g) the solid black line is the median and the shading is the interquartile range of data from all of the model trajectories. In (g) the individual trajectories are also shown with thin red lines. Observations are shown with diamonds (see text).

trajectories, which is driven by the near-surface temperature increasing more quickly along the trajectories than the SST, which results in a reduction in the air-sea temperature difference as shown in Fig. 13b.
The cloud-top height in the model is shown in Fig. 13d and indicates a gradual deepening of the boundary layer along the trajectories. This is in general accordance with the in situ measurements, although the model exhibits the same low bias in cloud-top height that was shown in Fig. 11b. The LWP and ice water path (IWP) data are shown in Figs. 13e and 13f. The LWP from the Nevzorov and MARSS data are indicated with open and filled diamonds, respectively. The error bars on the MARSS data represent the measured standard deviation along the distance covered by the aircraft during each profile. This again highlights the significant underestimate in the control model simulation of LWP in the stratiform region. After the transition, there is a reduction in the model LWP and a marked increase in the IWP variability and peak values. Although the control model has too much ice in the stratiform region, the shift to a higher IWP:LWP ratio is consistent with the observations that showed enhanced glaciation in the convective cloud region. The increase in the variability of IWP after the transition simply reflects the more variable nature of the cumulus clouds as compared to the overcast stratocumulus cloud along the trajectories.

Figure $13 \mathrm{~g}$ shows the peak surface precipitation rates along each of the individual trajectories. There is a gradual increase before the transition and then a rapid enhancement in peak precipitation rates after the transition as the cumulus clouds develop more fully. Finally, Fig. $13 \mathrm{~h}$ presents an analysis of the boundary layer types diagnosed by the model boundary layer scheme (Lock et al. 2000). For this cold-air-outbreak case the scheme identifies the following boundary layer types; a wellmixed stratocumulus layer, decoupled stratocumulus not over cumulus, decoupled stratocumulus over cumulus, and a cumulus capped layer. At each time point relative to the transition, the relative fraction of each boundary layer type from all of the model trajectories is calculated. This shows that before the transition the boundary layer is predominantly well mixed in accordance with the aircraft observations shown in Fig. 7. As the trajectories approach the transition in cloud fraction, there is an increase in the fraction of grid points that contain decoupled boundary layers (about $50 \%$ at the transition), and the majority of these are shallow cumulus rising into stratocumulus. Shallow cumulus clouds beneath the stratocumulus cloud deck were observed from the aircraft across the transition region on profile P7. After the transition, the fraction of decoupled boundary layer types continues to increase and there is an emergence of cumulus-capped boundary layer types.

The trajectory analysis from the control model shows that precipitation induced decoupling of the boundary layer plays a role in the breakup of the stratocumulus 
a)

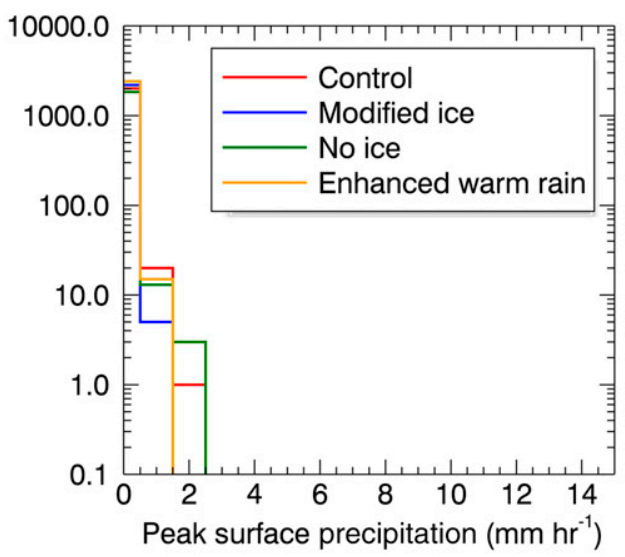

c)

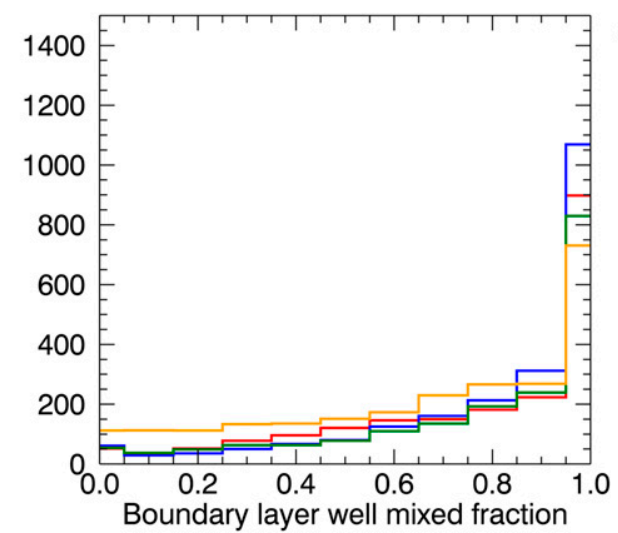

b)

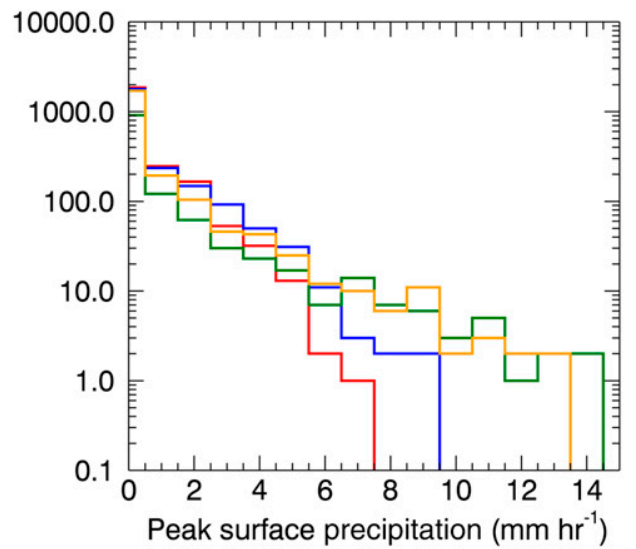

d)

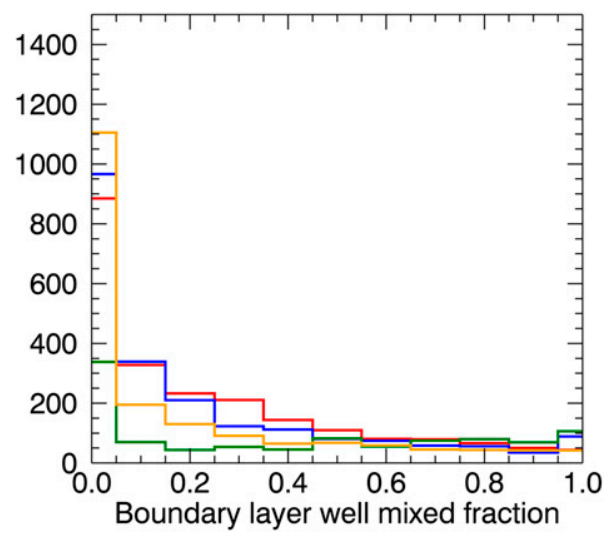

FIG. 14. Histograms showing the fraction of well-mixed boundary layers and the peak surface precipitation rate within a $10.5 \mathrm{~km} \times 10.5 \mathrm{~km}$ box surrounding each model trajectory. (a),(c) Data from 2 to $6 \mathrm{~h}$ before the transition in cloud fraction and (b),(d) data from 2 to $6 \mathrm{~h}$ after the transition. Model data from the control (red), modified-ice (blue), no-ice (green), and enhanced-warm-rain (orange) simulations are shown.

cloud layer. The different model simulations however transition between the stratiform and cumulus cloud regimes at different times and locations as shown in Fig. 9. To explore if there is commonality in the processes responsible for the breakup in the different model experiments, Fig. 14 compares the change in the surface precipitation rate and the fraction of boundary layer types that are diagnosed as being well mixed across the transition region. Histograms of the trajectory data from each experiment are shown for time periods covering $2-6 \mathrm{~h}$ before the transition and $-6 \mathrm{~h}$ after the transition. All of the simulations exhibit the same behavior, with a marked increase in surface precipitation rates across the transition in cloud regime that is coincident with a shift from a predominantly well-mixed to a predominantly decoupled boundary layer.

\section{Discussion and conclusions}

Aircraft observations of a Northern Hemisphere cold-air outbreak are used to characterize the properties of the mixed-phase stratocumulus-topped boundary layer and the subsequent breakup of the stratiform cloud layer into more open-cellular convection downwind. The measurements show a supercooled-liquid-dominated environment in the stratiform region. Cloud-top temperatures were $\sim-15^{\circ} \mathrm{C}$ and low number concentrations of ice particles were observed both within the cloud layer and precipitating beneath it. Across the transition in cloud morphology, there was a decoupling of the boundary layer structure with an emergence of more glaciated shallow cumulus clouds and a marked increase in precipitation. The increased ice-phase precipitation in the shallow cumulus clouds appeared to be consistent with a lowering of the cloud base, leading to in-cloud temperatures that were conducive to secondary ice production via the Hallett-Mossop rime-splintering mechanism. The scavenging of accumulation mode aerosols from precipitation processes across the transition in cloud regime exhibits remarkable similarities to the changes measured 
across transitions from closed- to open-cellular convection in POC events in the subtropics (Terai et al. 2014). Although modeling studies of POCs have highlighted that precipitation plays a key role in their initiation (e.g., Savic-Jovcic and Stevens 2008; Wang and Feingold 2009), in situ observations of POC formation remain elusive. The commonality of the observed features in this cold-air outbreak across the transition, such as the enhancement in precipitation, the subsequent depletion of aerosols, and a decoupling of the boundary layer structure indicate that similar mechanisms may be involved in the breakup of the cloud layer.

The observations are used to evaluate a series of cloud-resolving model simulations of this case study. The control model simulation had a significant low bias in LWP in the stratiform region, even though it included recent modifications to the ice particle riming and depositional growth rates that were designed to promote an increase in the liquid water content in mixed-phase boundary layer clouds (Furtado and Field 2017). This underestimate in LWP is a feature that is common to many models representation of mixedphase clouds in cold-air outbreaks (Klein et al. 2009; Field et al. 2017), in Arctic stratus clouds (Liu et al. 2011b; Forbes and Ahlgrimm 2014), and in the Southern Ocean (Kay et al. 2016). In the stratiform region, the model liquid and ice phases were shown to be generally well mixed, even though observations show that inhomogeneous mixtures of liquid drops and ice particles are more common in nature (e.g., Korolev et al. 2003; McFarquhar et al. 2007). A modification to the cloud scheme was therefore tested to limit the overlap between ice and liquid in the model grid box, in order to shield regions of liquid water from being depleted by ice particles via the Wegener-BergeronFindeisen and riming processes. This increased the LWP by a factor of $\sim 2$ in the stratiform cloud deck, although this was still lower than the observations. Obtaining values comparable to the observations could only be achieved by switching off all ice processes, highlighting that ice in the model is too active at removing supercooled liquid water from the stratiform cloud. Turning off ice in the model did however result in a marked delay in the timing of the transition to cumulus clouds, such that it occurred farther to the east than observed. Increasing the efficiency at which warm rain formed in the model in a simulation with no ice processes resulted in a more rapid breakup of the cloud layer and suppressing precipitation completely resulted in an almost completely overcast cloud field. The timing of the transition between closed-cellular convection and more cumuliform clouds in the model is therefore sensitive to the representation of the microphysics.

This was explored further by running pseudoLagrangian trajectories through the model domain in order to gain some insights into the processes responsible for the breakup of the cloud layer. The model was able to simulate many of the salient features shown in the observations across the transition in cloud regime. The simulation without precipitation resulted in very little breakup of the cloud field, suggesting that the strong surface fluxes were not the main driver for decoupling the boundary layer via the conceptual model of Bretherton and Wyant (1997). Furthermore, examination of the cloud-top entrainment instability parameter of Lock (2009) suggested that at the transition, any additional mixing of air across the inversion due to the shallow cumulus clouds rising into the overlying stratocumulus deck was also unlikely to promote breakup. Precipitation-induced decoupling of the boundary layer therefore appears to be the driving mechanism for the breakup. Evaporation of the precipitation leads to a cooling and moistening of the subcloud layer that decouples the stratocumulus cloud from the supply of moisture from the surface. There is a lowering of the lifting condensation level and shallow cumulus clouds form beneath the stratocumulus. The overlying stratiform cloud layer eventually thins owing to a loss of cloud water via precipitation and there is a shift to a cloud regime dominated by cumulus clouds. Although the position and timing of the transition between stratiform and more broken shallow cumulus clouds differ between model simulations, an enhancement in precipitation and a decoupling of the boundary layer at the transition are common features. Increasing the rate of precipitation formation results in an earlier transition due to more rapid decoupling and enhanced depletion of liquid water from the stratiform cloud layer.

The cloud drop number concentrations in the model are fixed in space and time and are derived from climatological aerosol concentrations (Walters et al. 2017), with values of $N_{d}$ typically between 40 and $60 \mathrm{~cm}^{-3}$ in the area of the aircraft operations. As no aerosol-cloud-precipitation feedbacks are included in the simulations, it is evident that in the model precipitation alone is sufficient to transition the cloud field from closed-cellular convection to a more broken cumuliform cloud field. This case study would however present a good opportunity to test more detailed microphysics schemes that include aerosol-cloudprecipitation interactions in order to examine if they can reproduce the observed rapid change in boundary layer aerosol conditions across the transition in cloud morphology. 
Additional work to improve the parameterization of mixed-phase clouds in the model is also clearly warranted in order to inhibit the significant depletion of liquid water by ice particles in supercooled layer clouds. The simulations showed that this had a marked impact on the cloud fraction and LWP and is therefore key to simulating the radiative impact of the cloud field. Improved observations of the spatial distribution of ice and liquid within the cloud would help guide changes such as that tested in the model cloud scheme. In addition, the use of higher-resolution large-eddy simulations would also provide guidance on this aspect but also enable the detailed cloud and boundary layer dynamics to be better resolved, which are key to forming the balance between the generation of liquid water in updrafts and the depletion of liquid water through precipitation. Furthermore, secondary ice processes appear to be important in the development of precipitation in the cumulus clouds measured in this case study but are not represented in the model microphysics scheme.

Acknowledgments. Pete Francis is thanked for providing the MSG data. MODIS L1A and L1B data were acquired from the Level-1 \& Atmosphere Archive and Distribution System (LAADS) Distributed Active Archive Center (DAAC). AMSR data are produced by Remote Sensing Systems and were sponsored by the NASA AMSR-E Science Team and the NASA Earth Science Making Earth Science Data Records for Use in Research Environments (MEaSUREs) Program. Data are available online (at www.remss.com). Airborne data were obtained using the FAAM BAe-146 Atmospheric Research Aircraft, which was operated by Airtask and jointly funded by the U.K. Natural Environment Research Council (NERC) and the Met Office. The University of Manchester acknowledges support from NERC under Grant NE/I028696/1 as part of the Aerosol-Cloud Coupling and Climate Interactions in the Arctic (ACCACIA) project.

\section{APPENDIX}

\section{Ice Cloud Fraction Parameterization}

The ice cloud fraction parameterization in highresolution versions of the $\mathrm{UM}$ is constructed by analogy to the liquid cloud fraction parameterization of Smith (1990). In this formulation, the ice cloud mass $q_{\mathrm{cf}}$ is prognosed from microphysical process rates, and the ice cloud fraction $C_{f}$ is diagnosed from $q_{\mathrm{cf}}$ using

$$
C_{f}= \begin{cases}0, & q_{\mathrm{cf}}=0 \\ \frac{1}{2}\left(6 \frac{q_{\mathrm{cf}}}{b_{s i}}\right)^{2 / 3}, & 0<\frac{q_{\mathrm{cf}}}{b_{s i}} \leq \frac{1}{6} \\ 1-4 \cos ^{2} \phi, & \frac{1}{6}<\frac{q_{\mathrm{cf}}}{b_{s i}}<1 \\ 1, & 1 \leq \frac{q_{\mathrm{cf}}}{b_{s i}}\end{cases}
$$

where $\phi=(1 / 3)\left\{\cos ^{-1}\left[3 /\left(2^{3 / 2}\right)\right]\left(1-2 q_{\mathrm{cf}} / b_{s i}\right)+4 \pi\right\}$ and

$$
\frac{q_{\mathrm{cf}}}{b_{s i}}=\frac{q_{\mathrm{cf}}}{\left(1-\mathrm{RH}_{\text {crit }}\right) q_{\text {satliq }}},
$$

$\mathrm{RH}_{\text {crit }}$ being the critical relative humidity for cloud formation, $q_{\text {satliq }}$ being the saturation specific humidity with respect to liquid water, and $b_{s i}$ representing the apparent half-width of the ice probability density function (PDF). After calculation of $C_{f}$ using Eq. (A1), its value is then further adjusted based on the empirical relationship established in Wood and Field (2000).

While the formalism of Eq. (A1) and the empirical relationship of Wood and Field (2000) are well established for liquid clouds, there is no formal basis for its applicability to mixed-phase clouds. Therefore, the modified-ice simulation makes two adjustments to this parameterization. First, we rewrite Eq. (A2) as

$$
\frac{q_{\mathrm{cf}}}{b_{s i}}=\frac{q_{\mathrm{cf}}}{\left(1-\mathrm{RH}_{\text {crit }}\right) q_{\text {satliq }}} \max \left(1-C_{\text {lmax }}, 0.05\right) \text {, }
$$

where $C_{l \max }$ is the maximum liquid cloud fraction in the cloud layer. This is based on the idea that even at kilometer scale, ice and liquid are not homogeneously mixed and that the region of the model grid box where there is an interface between ice and liquid can be much smaller than the total gridbox volume. This is likely to be the case in the stratiform cloud layer as the observations show that the concentration of liquid cloud drops are $\sim 5 \times 10^{4}$ more numerous than the ice particles (see Fig. 3). Therefore, we are explicitly forcing the ice cloud fraction to be lower (via a decrease in $q_{\mathrm{cf}} / b_{s i}$ ) when liquid cloud fractions are high, thus limiting the overlap between ice and liquid phases. For liquid clouds, $b_{s}$ represents the half-width of a PDF for subgrid fluctuations in temperature and humidity, and while this analogy does not strictly hold true for ice clouds (because large supersaturations can exist), this modification can be thought of as increasing $b_{s i}$ in proportion to $C_{l}$ (i.e., making the PDF wider and more inhomogeneous). Further discussion on this can be found in Tan and Storelvmo (2016).

The second modification we apply in the modified-ice simulation is to remove the empirical adjustment to the 
ice cloud fraction. The observations of Wood and Field (2000) on which this adjustment is based are all from liquid only clouds or cirrus clouds that contain no liquid water, and therefore there is little evidence that this adjustment should be applicable in mixed-phase clouds.

\section{REFERENCES}

Abel, S. J., and I. A. Boutle, 2012: An improved representation of the raindrop size distribution for single-moment microphysics schemes. Quart. J. Roy. Meteor. Soc., 138, 2151-2162, doi:10.1002/ qj.1949.

Beswick, K. M., M. W. Gallagher, A. R. Webb, E. G. Norton, and F. Perry, 2008: Application of the Aventech AIMMS20AQ airborne probe for turbulence measurements during the Convective Storm Initiation Project. Atmos. Chem. Phys., 8, 5449-5463, doi:10.5194/acp-8-5449-2008.

Bodas-Salcedo, A., K. D. Williams, P. R. Field, and A. P. Lock, 2012: The surface downwelling solar radiation surplus over the Southern Ocean in the Met Office model: The role of midlatitude cyclones. J. Climate, 25, 7467-7486, doi:10.1175/ JCLI-D-11-00702.1.

- , and Coauthors, 2014: Origins of the solar radiation biases over the Southern Ocean in CFMIP2 models. J. Climate, 27, 41-56, doi:10.1175/JCLI-D-13-00169.1.

—, P. G. Hill, K. Furtado, K. D. Williams, P. R. Field, J. C. Manners, and P. Hyder, 2016: Large contribution of supercooled liquid clouds to the solar radiation budget of the Southern Ocean. J. Climate, 29, 4213-4228, doi:10.1175/JCLI-D-15-0564.1.

Boutle, I. A., and S. J. Abel, 2012: Microphysical controls on the stratocumulus topped boundary-layer structure during VOCALS-REx. Atmos. Chem. Phys., 12, 2849-2863, doi:10.5194/acp-12-2849-2012.

— J. E. J. Eyre, and A. P. Lock, 2014: Seamless stratocumulus simulation across the turbulent gray zone. Mon. Wea. Rev., 142, 1655-1668, doi:10.1175/MWR-D-13-00229.1.

Bretherton, C. S., and M. C. Wyant, 1997: Moisture transport, lower-tropospheric stability, and decoupling of cloud-topped boundary layers. J. Atmos. Sci., 54, 148-167, doi:10.1175/ 1520-0469(1997)054<0148:MTLTSA > 2.0.CO;2.

Brümmer, B., 1996: Boundary-layer modification in wintertime cold-air outbreaks from the Arctic sea ice. Bound.-Layer Meteor., 80, 109-125, doi:10.1007/BF00119014.

__ 1999: Roll and cell convection in wintertime Arctic coldair outbreaks. J. Atmos. Sci., 56, 2613-2636, doi:10.1175/ 1520-0469(1999)056<2613:RACCIW >2.0.CO;2.

Crosier, J., and Coauthors, 2011: Observations of ice multiplication in a weakly convective cell embedded in supercooled midlevel stratus. Atmos. Chem. Phys., 11, 257-273, doi:10.5194/ acp-11-257-2011.

Ellison, W. J., 2007: Permittivity of pure water, at standard atmospheric pressure, over the frequency range $0-25 \mathrm{Thz}$ and the temperature range $0-100^{\circ}$ C. J. Phys. Chem. Ref. Data, 36, $1-$ 18, doi:10.1063/1.2360986.

English, S. J., 1995: Airborne radiometric observations of cloud liquid-water emission at 89 and $157 \mathrm{GHz}$ : Application to retrieval of liquid-water path. Quart. J. Roy. Meteor. Soc., 121, 1501-1524, doi:10.1002/qj.49712152702.

Eriksson, P., S. A. Buehler, C. P. Davis, C. Emde, and O. Lemke, 2011: ARTS, the atmospheric radiative transfer simulator, version 2. J. Quant. Spectrosc. Radiat. Transfer, 112, 15511558, doi:10.1016/j.jqsrt.2011.03.001.
Field, P. R., A. J. Heymsfield, and A. Bansemer, 2006: Shattering and particle interarrival times measured by optical array probes in ice clouds. J. Atmos. Oceanic Technol., 23, 13571371, doi:10.1175/JTECH1922.1.

,-- , and -2007 : Snow size distribution parameterization for midlatitude and tropical ice clouds. J. Atmos. Sci., 64, 43464365, doi:10.1175/2007JAS2344.1.

- R. J. Cotton, K. McBeath, A. P. Lock, S. Webster, and R. P. Allan, 2014: Improving a convection-permitting model simulation of a cold air outbreak. Quart. J. Roy. Meteor. Soc., 140, 124-138, doi:10.1002/qj.2116.

- - and Coauthors, 2017: Exploring the convective grey zone with regional simulations of a cold air outbreak. Quart. J. Roy. Meteor. Soc., doi:10.1002/qj.3105, in press.

Fletcher, J., S. Mason, and C. Jakob, 2016: The climatology, meteorology, and boundary layer structure of marine cold air outbreaks in both hemispheres. J. Climate, 29, 1999-2014, doi:10.1175/JCLI-D-15-0268.1.

Forbes, R. M., and M. Ahlgrimm, 2014: On the representation of high-latitude boundary layer mixed-phase cloud in the ECMWF global model. Mon. Wea. Rev., 142, 3425-3445, doi:10.1175/MWR-D-13-00325.1.

Furtado, K., and P. Field, 2017: The role of ice microphysics parametrizations in determining the prevalence of supercooled liquid water in high-resolution simulations of a Southern Ocean midlatitude cyclone. J. Atmos. Sci., 74, 2001-2021, doi:10.1175/JAS-D-16-0165.1.

Hallett, J., and S. C. Mossop, 1974: Production of secondary ice particles during the riming process. Nature, 249, 26-28, doi:10.1038/ $249026 a 0$.

Harden, B. E., I. A. Renfrew, and G. N. Petersen, 2015: Meteorological buoy observations from the central Iceland Sea. J. Geophys. Res. Atmos., 120, 3199-3208, doi:10.1002/ 2014JD022584.

Jones, C. R., C. S. Bretherton, and D. Leon, 2011: Coupled vs. decoupled boundary layers in VOCALS-REx. Atmos. Chem. Phys., 11, 7143-7153, doi:10.5194/acp-11-7143-2011.

Kay, J. E., C. Wall, V. Yettella, B. Medeiros, C. Hannay, P. Caldwell, and C. Bitz, 2016: Global climate impacts of fixing the Southern Ocean shortwave radiation bias in the Community Earth System Model (CESM). J. Climate, 29, 4617-4636, doi:10.1175/JCLI-D-15-0358.1.

Klein, S. A., and Coauthors, 2009: Intercomparison of model simulations of mixed-phase clouds observed during the ARM Mixed-Phase Arctic Cloud Experiment. I: Single-layer cloud. Quart. J. Roy. Meteor. Soc., 135, 979-1002, doi:10.1002/qj.416.

Kolstad, E. W., T. J. Bracegirdle, and I. A. Seierstad, 2009: Marine cold-air outbreaks in the northern Atlantic: Temporal distribution and associations with large-scale atmospheric circulation. Climate Dyn., 33, 187-197, doi:10.1007/s00382-008-0431-5.

Korolev, A., G. A. Isaac, S. G. Cober, J. W. Strapp, and J. Hallett, 2003: Microphysical characterization of mixedphase clouds. Quart. J. Roy. Meteor. Soc., 129, 39-65, doi:10.1256/qj.01.204.

_ , E. Emery, and K. Creelman, 2013a: Modification and tests of particle probe tips to mitigate effects of ice shattering. J. Atmos. Oceanic Technol., 30, 690-708, doi:10.1175/JTECH-D-12-00142.1.

, J. W. Strapp, and G. A. Isaac, 2013b: Improved airborne hot-wire measurements of ice water content in clouds. J. Atmos. Oceanic Technol., 30, 2121-2131, doi:10.1175/JTECH-D-13-00007.1.

Liu, Q., F. Weng, and S. J. English, 2011a: An improved fast microwave water emissivity model. IEEE Trans. Geosci. Remote Sens., 49, 1238-1250, doi:10.1109/TGRS.2010.2064779. 
Liu, X., and Coauthors, 2011b: Testing cloud microphysics parameterizations in NCAR CAM5 with ISDAC and M-PACE observations. J. Geophys. Res., 116, D00T11, doi:10.1029/ 2011JD015889.

Lock, A. P., 2009: Factors influencing cloud area and at the capping inversion for shallow cumulus clouds. Quart. J. Roy. Meteor. Soc., 135, 941-952, doi:10.1002/qj.424.

—, A. R. Brown, M. R. Bush, G. M. Martin, and R. N. B. Smith, 2000: A new boundary layer mixing scheme. Part I: Scheme description and single-column model tests. Mon. Wea. Rev., 128, 3187-3199, doi:10.1175/1520-0493(2000)128<3187:ANBLMS > 2.0.CO;2.

McFarquhar, G. M., G. Zhang, M. R. Poellot, G. L. Kok, R. McCoy, T. Tooman, A. Fridlind, and A. J. Heymsfield, 2007: Ice properties of single-layer stratocumulus during the Mixed-Phase Arctic Cloud Experiment: 1. Observations. J. Geophys. Res., 112, D24201, doi:10.1029/2007JD008633.

McGrath, A., and T. Hewison, 2001: Measuring the accuracy of MARSS-An airborne microwave radiometer.J. Atmos. Oceanic Technol., 18, 2003-2012, doi:10.1175/1520-0426(2001)018<2003: MTAOMA $>2.0 . \mathrm{CO} ; 2$.

Morrison, H., G. de Boer, G. Feingold, J. Harrington, M. D. Shupe, and K. Sulia, 2012: Resilience of persistent Arctic mixed-phase clouds. Nat. Geosci., 5, 11-17, doi:10.1038/ngeo1332.

Nicholls, S., J. Leighton, and R. Barker, 1990: A new fast response instrument for measuring total water content from aircraft. J. Atmos. Oceanic Technol., 7, 706-718, doi:10.1175/ 1520-0426(1990)007<0706:ANFRIF > 2.0.CO;2.

Petters, M. D., J. R. Snider, B. Stevens, G. Vali, I. Faloona, and L. M. Russell, 2006: Accumulation mode aerosol, pockets of open cells, and particle nucleation in the remote subtropical Pacific marine boundary layer. J. Geophys. Res., 111, D02206, doi:10.1029/2004JD005694.

Rodgers, C. D., 1976: Retrieval of atmospheric temperature and composition from remote measurements of thermal radiation. Rev. Geophys., 14, 609-624, doi:10.1029/RG014i004p00609.

Sandu, I., and B. Stevens, 2011: On the factors modulating the stratocumulus to cumulus transitions. J. Atmos. Sci., 68, 18651881, doi:10.1175/2011JAS3614.1.

,-- , and R. Pincus, 2010: On the transitions in marine boundary layer cloudiness. Atmos. Chem. Phys., 10, 23772391, doi:10.5194/acp-10-2377-2010.

Savic-Jovcic, V., and B. Stevens, 2008: The structure and mesoscale organization of precipitating stratocumulus. J. Atmos. Sci., $\mathbf{6 5}$, 1587-1605, doi:10.1175/2007JAS2456.1.

Schmetz, J., P. Pili, S. Tjemkes, D. Just, J. Kerkmann, S. Rota, and A. Ratier, 2002: An introduction to Meteosat Second Generation (MSG). Bull. Amer. Meteor. Soc., 83, 977-992, doi:10.1175/1520-0477(2002)083<0977:AITMSG > 2.3.CO;2.

Sharon, T. M., B. A. Albrecht, H. H. Jonsson, P. Minnis, M. M. Khaiyer, T. M. van Reken, J. Seinfeld, and R. Flagan, 2006: Aerosol and cloud microphysical characteristics of rifts and gradients in maritime stratocumulus clouds. J. Atmos. Sci., 63, 983-997, doi:10.1175/JAS3667.1.

Smith, R. N. B., 1990: A scheme for predicting layer clouds and their water content in a general circulation model. Quart. J. Roy. Meteor. Soc., 116, 435-460, doi:10.1002/qj.49711649210.

Tan, I., and T. Storelvmo, 2016: Sensitivity study on the influence of cloud microphysical parameters on mixed-phase cloud thermodynamic phase partitioning in CAM5. J. Atmos. Sci., 73, 709-728, doi:10.1175/JAS-D-15-0152.1.

Terai, C. R., C. S. Bretherton, R. Wood, and G. Painter, 2014: Aircraft observations of aerosol, cloud, precipitation, and boundary layer properties in pockets of open cells over the southeast Pacific. Atmos. Chem. Phys., 14, 8071-8088, doi:10.5194/ acp-14-8071-2014.

Turner, D. D., S. Kneifel, and M. P. Cadeddu, 2016: An improved liquid water absorption model at microwave frequencies for supercooled liquid water clouds. J. Atmos. Oceanic Technol., 33, 33-44, doi:10.1175/JTECH-D-15-0074.1.

Walters, D., and Coauthors, 2017: The Met Office Unified Model Global Atmosphere 6.0/6.1 and JULES Global Land 6.0/6.1 configurations. Geosci. Model Dev., 10,1487-1520, doi:10.5194/ gmd-10-1487-2017.

Wang, H., and G. Feingold, 2009: Modeling mesoscale cellular structures and drizzle in marine stratocumulus. Part I: Impact of drizzle on the formation and evolution of open cells. J. Atmos. Sci., 66, 3237-3256, doi:10.1175/ 2009JAS3022.1.

Wentz, F. J., and R. W. Spencer, 1998: SSM/I rain retrievals within a unified all-weather ocean algorithm. J. Atmos. Sci., 55, 1613-1627, doi:10.1175/1520-0469(1998)055<1613: SIRRWA $>2.0 . \mathrm{CO} ; 2$.

Williams, K. D., and Coauthors, 2013: The Transpose-AMIP II experiment and its application to the understanding of Southern Ocean cloud biases in climate models. J. Climate, 26, 3258-3274, doi:10.1175/JCLI-D-12-00429.1.

Wood, N., and Coauthors, 2014: An inherently mass-conserving semi-implicit semi-Lagrangian discretization of the deepatmosphere global non-hydrostatic equations. Quart. J. Roy. Meteor. Soc., 140, 1505-1520, doi:10.1002/qj.2235.

Wood, R., and P. R. Field, 2000: Relationships between total water, condensed water, and cloud fraction in stratiform clouds examined using aircraft data. J. Atmos. Sci., 57, 1888-1905, doi:10.1175/1520-0469(2000)057<1888:RBTWCW>2.0.CO;2.

$\longrightarrow$, K. K. Comstock, C. S. Bretherton, C. Cornish, J. Tomlinson, D. R. Collins, and C. Fairall, 2008: Open cellular structure in marine stratocumulus sheets. J. Geophys. Res., 113, D12207, doi:10.1029/2007JD009371.

Zuidema, P., D. Leon, A. Pazmany, and M. Cadeddu, 2012: Aircraft millimeter-wave passive sensing of cloud liquid water and water vapor during VOCALS-REx. Atmos. Chem. Phys., 12, 355-369, doi:10.5194/acp-12-355-2012. 